Article

\title{
Digital Aerial Photogrammetry for Uneven-Aged Forest Management: Assessing the Potential to Reconstruct Canopy Structure and Estimate Living Biomass
}

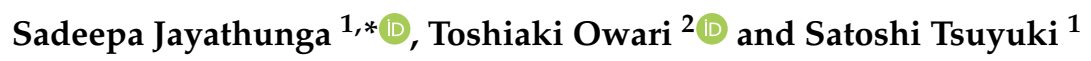 \\ 1 Department of Global Agricultural Sciences, Graduate School of Agricultural and Life Sciences, \\ The University of Tokyo, Tokyo 113-8657, Japan; tsuyuki@fr.a.u-tokyo.ac.jp \\ 2 The University of Tokyo Chiba Forest, Graduate School of Agricultural and Life Sciences, The University of \\ Tokyo, Kamogawa, Chiba 299-5503, Japan; owari@uf.a.u-tokyo.ac.jp \\ * Correspondence: ajayathungasadeepa@g.ecc.u-tokyo.ac.jp; Tel.: +81-3-5841-7509; Fax: +81-3-5841-5235
}

Received: 20 December 2018; Accepted: 6 February 2019; Published: 8 February 2019

\begin{abstract}
Scientifically robust yet economical and efficient methods are required to gather information about larger areas of uneven-aged forest resources, particularly at the landscape level, to reduce deforestation and forest degradation and to support the sustainable management of forest resources. In this study, we examined the potential of digital aerial photogrammetry (DAP) for assessing uneven-aged forest resources. Specifically, we tested the performance of biomass estimation by varying the conditions of several factors, e.g., image downscaling, vegetation metric extraction (point cloud- and canopy height model (CHM)-derived), modeling method ((simple linear regression (SLR), multiple linear regression (MLR), and random forest (RF)), and season (leaf-on and leaf-off). We built dense point clouds and CHMs using high-resolution aerial imagery collected in leaf-on and leaf-off conditions of an uneven-aged mixed conifer-broadleaf forest. DAP-derived vegetation metrics were then used to predict the dominant height and living biomass (total, conifer, and broadleaf) at the plot level. Our results demonstrated that image downscaling had a negative impact on the accuracy of the dominant height and biomass estimation in leaf-on conditions. In comparison to $\mathrm{CHM}$-derived vegetation metrics, point cloud-derived metrics performed better in dominant height and biomass (total and conifer) estimations. Although the SLR (\%RMSE $=21.1)$ and MLR $(\%$ RMSE $=18.1)$ modeling methods produced acceptable results for total biomass estimations, RF modeling significantly improved the plot-level total biomass estimation accuracy (\%RMSE of 12.0 for leaf-on data). Overall, leaf-on DAP performed better in total biomass estimation compared to leaf-off DAP (\%RMSE of 15.0 using RF modeling). Nevertheless, conifer biomass estimation accuracy improved when leaf-off data were used (from a \%RMSE of 32.1 leaf-on to 23.8 leaf-off using RF modeling). Leaf-off DAP had a negative impact on the broadleaf biomass estimation (\%RMSE > 35\% for SLR, MLR, and RF modeling). Our results demonstrated that the performance of forest biomass estimation for uneven-aged forests varied with statistical representations as well as data sources. Thus, it would be appropriate to explore different statistical approaches (e.g., parametric and nonparametric) and data sources (e.g., different image resolutions, vegetation metrics, and leaf-on and leaf-off data) to inform the interpretation of remotely sensed data for biomass estimation for uneven-aged forest resources.
\end{abstract}

Keywords: unmanned aerial vehicle; mixed conifer-broadleaf forest; leaf-off imagery 


\section{Introduction}

Deforestation and forest degradation are among the most significant environmental issues of our time. Particularly, during the past few decades, natural forest cover has been reduced dramatically in most parts of the world due to various natural and anthropogenic processes [1,2]. In such scenarios, the acquisition of comprehensive, timely, and reliable information about forest resources is crucial for the sustainable utilization of natural forest resources, as well as for supporting programs (e.g., REDD+) that are dedicated to combating deforestation and forest degradation [2-4].

In addition, there is currently a gradual shift from pure even-aged management to uneven-aged management of forests throughout the world as a result of the increasing criticism of even-aged silviculture, particularly in light of the strong and mostly negative impacts of clear-felling on ecosystem services, including habitat quality and outdoor recreation [5,6]. Basically, uneven-aged forest management aims to create and maintain stands with an uneven tree age structure through selection harvesting, i.e., the removal of individual trees (single tree selection) or groups of trees (group selection) [5-7]. Thus, uneven-aged forests tend to have complex structural and spatial arrangements. It is often reasoned that with proper management planning, uneven-aged management has the potential to become fully competitive with existing even-aged management [8].

However, to achieve the goals of uneven-aged forest management, decisions must be made in a complex, ever-changing environment with a wide variety of stakeholders. Thus, uneven-aged forest management planning requires substantial amounts of data that can provide quantitative and qualitative information about forest resources [5,6]. Because of the relatively high structural and spatial complexity of uneven-aged forests, the acquisition of data could be even more challenging than in even-aged forests and forest types with relatively simple forest structures. Thus, scientifically robust yet economical and efficient methods are required to gather information about larger areas of uneven-aged forest resources, particularly at the landscape, regional, or global levels. Nevertheless, when conducting forest resource assessments over large areas (e.g., forest enterprise, national and regional levels), traditional ground-based techniques have proven to be less effective in terms of resource requirement (e.g., time, labor, cost, etc.) $[9,10]$, as well as in the provision of information about spatial variations (due to a limited number of sample plots) [11]. By addressing the limitations of ground surveys, remote sensing (RS) techniques may bridge the gap between the need for an efficient method of reliable data acquisition and extensive resource requirements.

Both active and passive RS methods often complement traditional ground-based surveys by contributing reliable and detailed information on various aspects of forest structure with varying levels of spatial, spectral, and temporal resolutions [12-14]. Particularly, RS techniques such as airborne light detection and ranging (LiDAR) and digital aerial photogrammetry (DAP), which facilitate the reconstruction of three-dimensional (3D) vegetation structures $[15,16]$, have become important tools over time for a broad range of scientific and environmental management applications, including natural resource management. Particularly, in forestry, the use of DAP datasets has become increasingly common for studying vegetation structure [17], estimating forest structural attributes (including height, diameter, basal area, aboveground biomass, and carbon) [18-20], monitoring forest recovery and regeneration [21,22], and modeling various forest ecosystem processes [23,24].

DAP is based on the fundamental concepts of traditional stereophotogrammetry, but involves the comprehensive use of digital tools and takes advantage of automated processes [25]. For instance, nowadays, many commercial and open-source software packages, e.g., IMAGINE Photogrammetry (Hexagon Geospatial, Alabama, USA), PHOTOMOD (RACURS, Moscow, Russia), Trimble Inpho (Trimble Geospatial Inc, California, USA), Agisoft PhotoScan (Agisoft LLC, St Petersburg, Russia), pix4D (pix4D Inc., Lausanne, Switzerland), and Micmac (open source), are available to perform DAP with imagery that is acquired using consumer-grade cameras. The increased availability of small unmanned aerial vehicles (UAVs) [26,27], which can be easily equipped with consumer-grade cameras, has made the acquisition of aerial imagery more efficient and economical and has further supported the wide applicability of DAP techniques [28,29]. Developments in the Global Navigational Satellite 
System (GNSS) and inertial measurement units (IMUs) have also significantly contributed to the high positional accuracy of DAP techniques, while the introduction of graphic processing units (GPUs) has increased the computational capabilities used for data processing [30,31]. In brief, all of these improvements have significantly cut costs, reduced processing time, and allowed even non-experts to successfully utilize DAP for various purposes [32]. Thus, DAP has become an effective tool for many forestry applications, including forest resource assessment.

During the last decade, there has been a growing interest among the scientific community to use DAP for assessing forest resources. Many studies have used various DAP products (e.g., point clouds, canopy models, orthomosaics) to quantify, assess, and monitor forest resources over a range of forest types $[16,17,21,33-35]$. Such forest resource assessments have been based either on individual tree detection (ITD) or the area-based approach (ABA). The ABA is increasingly popular due to its relatively high efficiency over a range of forest types, including uneven-aged forests [34,36,37], and in non-forest settings, e.g., small overlapping plants in savannah ecosystems [38]. The ABA has been proven to produce reliable information (e.g., plot- and stand-level estimations, wall-to-wall maps) over large areas of uneven-aged forest resources where ITD is particularly challenging due to dense overlapping tree crowns. Although previous studies have demonstrated the ability of digital photogrammetric products to offer an alternative data source for high-cost 3D RS techniques, such as airborne LiDAR [39], there is still a need for further investigation of the optimal conditions for using aerial imagery for the assessment of uneven-aged forest resources. Therefore, in this study, we examined the potential of high-resolution aerial imagery for assessing uneven-aged forest resources. This subject has received little study to date, and we especially focused on improving the method's accuracy.

An area-based forest resource assessment using DAP products involves (1) building 3D point clouds from aerial imagery, (2) developing canopy height models (CHMs), (3) extracting various vegetation metrics, and (4) modeling forest structural attributes of interest using vegetation metrics. Considering these steps, we identified image resolution [40], 3D products (point cloud and CHM) for vegetation metric extraction [41], modeling methods [12], and season of image acquisition [42] as some of the aspects that could play an important role in the accuracy of forest resource assessment over uneven-aged forest resources. Thus, in this study, we tested the performance of forest structural attribute estimation in varying conditions, such as image downscaling, photogrammetric products (point cloud and $\mathrm{CHM}$ ), modeling methods, and seasons, using two commonly used forest structural attributes, i.e., dominant height $\left(h_{\text {dom }}\right)$ and living biomass.

\section{Materials and Methods}

\subsection{Study Site}

This study was conducted in the University of Tokyo Hokkaido Forest (UTHF) (Figure 1a,b). UTHF is a pan-mixed conifer-broadleaf forest [43] located in Furano City, central Hokkaido Island, northern Japan $\left(43^{\circ} 10-20^{\prime} \mathrm{N}, 142^{\circ} 18-40^{\prime} \mathrm{E}, 189-1459 \mathrm{~m}\right.$ a.s.l.). The mean annual temperature at the site ( $230 \mathrm{~m}$ a.s.l.) between 2001 and 2008 was $6.4{ }^{\circ} \mathrm{C}$ (maximum of $35.4^{\circ} \mathrm{C}$ and minimum of $-26.8^{\circ} \mathrm{C}$ ). Snow covers the ground from late November to early April, with a maximum depth of about $1 \mathrm{~m}$. The total area of the UTHF (22,715 ha) is divided into compartments of $\sim 300$ ha each, and selected compartments are subjected to silvicultural activities each year. The specific area of interest (AOI) included forest management Compartment 48 (340 ha) (Figure 1b,c), which was scheduled to be managed from 2017 onward. The elevation of the AOI ranges from 400 to 835 (m a.s.1.). Following a forest resource inventory, silvicultural activities, such as selection harvesting and enrichment planting, are carried out throughout the compartment, except in reserved forest areas (e.g., riverine forests and forest areas on steep slopes).

Abies sachalinensis (Sakhalin fir), one of the dominant tree species in the pan-mixed forest type, grows here at a wide range of elevations (from 200 to about $1200 \mathrm{~m}$ a.s.l). Other conifer tree species found in the AOI include Picea jezoensis, Taxus cuspidata, P. glehnii, and Larix kaempferi. Betula ermanii is 
the dominant deciduous species found in the AOI. B. maximowicziana, Tilia japonica, Acer spp., Salix spp., Quercus crispula, Kalopanax septemlobus, and Fraxinus mandshurica are among the common deciduous species found in the AOI. The forest floor is often occupied by dwarf bamboo (Sasa senanensis and Sasa kurilensis). A part of the forest area in this compartment is secondary forest recovering from heavy typhoon damage that occurred in 1981. The forest floor of some heavily damaged areas was scarified and subsequently restored by planting conifer species. The AOI comprises forest areas with different levels of canopy structural and spatial complexity that developed as a result of previous disturbances and silvicultural activities. The different forest stand types found in the AOI include young broadleaf, young conifer, sparse forest, conifer-dominated mixed, broadleaf-dominated mixed, reserve forest, and plantations.

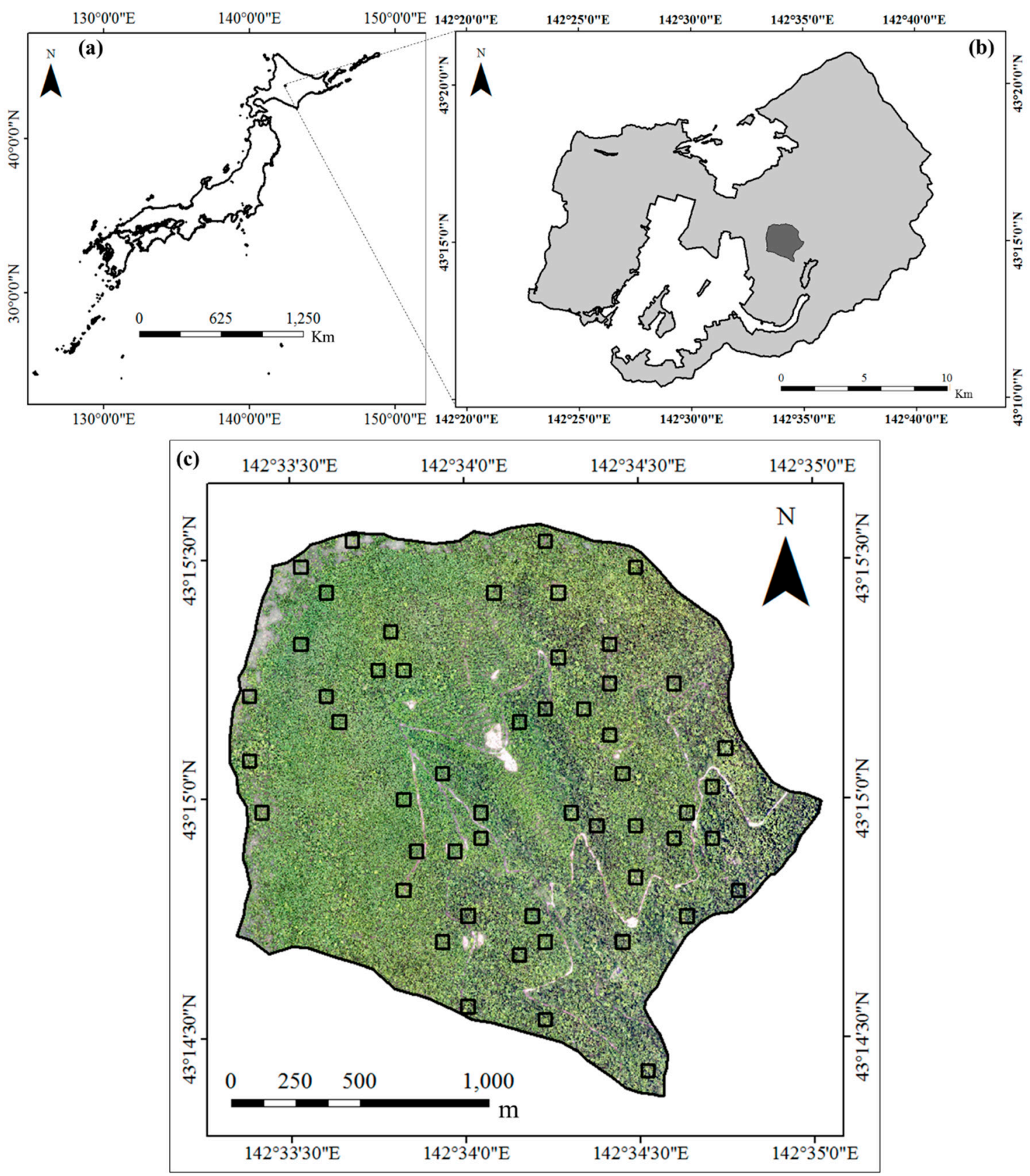

Figure 1. Location of University of Tokyo Hokkaido Forest (UTHF) (a), location of the area of interest (AOI) inside UTHF (b), and leaf-on digital aerial photogrammetry (DAP) orthomosaic ( $0.5 \mathrm{~m}$ resolution) of Compartment 48 and locations of the sample plots (c). 


\subsection{Data}

\subsubsection{Field Data}

We used a 2017 forest inventory dataset from UTHF to select 52 sample plots that were established completely inside the boundary of the AOI (Figure 1c). These sample plots $(50 \times 50 \mathrm{~m}$ each) represent the major forest stand types of the AOI. One corner position of each sample plot was determined by a differential GPS, while the remaining corner positions were determined using a laser range finder and a compass. In each sample plot, the diameters at breast height (DBH) and the species names of all trees with $\mathrm{DBH} \geq 5 \mathrm{~cm}$ were recorded. The plot size and DBH threshold for measurement were determined according to the common inventory practice of UTHF [44] and the national forest inventory (NFI) guidelines of Japan [45]. The inventory datasets did not include any tree height measurements. Therefore, soon after completing the general forest inventory, we conducted a separate field survey of 46 sample plots (chosen from the original inventory plots) to measure tree height. Considering the previous literature on the definition of dominant height [46] and the resource (time and labor) requirements for measurements, in each plot 8 trees with the largest DBH were measured. The top and bottom of each individual tree were measured using a Vertex laser hypsometer (Haglof, Inc., Långsele, Sweden) to get the actual tree height. Three measurements were taken without changing the standing position, and the average of the three measurements was recorded as the individual tree height. Six of the 46 sample plots with height measurements were 0.125 ha in size, and they were excluded from this study because their plot sizes were smaller than the majority of the plots. The volume of individual trees was calculated from the $\mathrm{DBH}$ values using one variable $V$ function that was developed specifically for the common conifer and broadleaf species found in the UTHF [47,48]. The living biomass of individual trees was calculated to comply with the definitions used by the greenhouse gas inventory office of Japan (GIO) using the following equation:

$$
\text { Biomass }=\sum_{j}\left\{\left[V_{j} \times D_{j} \times B E F_{j}\right] \times\left(1+R_{j}\right)\right\},
$$

where Biomass is the living biomass $\left(\mathrm{Mg} \mathrm{ha}^{-1}\right), V$ is the merchantable volume $\left(\mathrm{m}^{3} \mathrm{ha}^{-1}\right), D$ is the wood density (t-d.m. $\mathrm{m}^{-3}$ ), BEF is the biomass expansion factor for the conversion of volume, $R$ is the root-to-shoot ratio, and $j$ is the tree species. The $B E F, D$, and $R$ values that have been suggested by the GIO on the basis of research work in Japan [49] were used in this study.

A summary of field-measured forest structural attributes is presented in Table 1.

Table 1. Forest structural characteristics at the AOI $(n=52$, plot size $=0.25$ ha $)$.

\begin{tabular}{cccc}
\hline Field Attributes & Unit & Mean (SD) & Range \\
\hline Dominant height $\left(h_{\text {dom }}\right)$ & $\mathrm{M}$ & $22.0(4.2)$ & $15.2-30.0$ \\
Mean DBH $(D)$ & $\mathrm{Cm}$ & $13.3(3.9)$ & $6.5-20.9$ \\
Basal area $(B A)$ & $\mathrm{m}^{2} \mathrm{ha}^{-1}$ & $23.1(8.6)$ & $7.1-39.7$ \\
Living tree biomass (total biomass) & $\mathrm{Mg} \mathrm{ha}^{-1}$ & $140(65.5)$ & $45.8-275.1$ \\
Living biomass of conifer trees (conifer biomass) & $\mathrm{Mg} \mathrm{ha}^{-1}$ & $42.1(43.3)$ & $0.13-150.1$ \\
Living biomass of broadleaf trees (broadleaf biomass) & $\mathrm{Mg} \mathrm{ha}^{-1}$ & $98.3(38.5)$ & $41.78-235.2$ \\
Stem density $(N)$ & $\mathrm{ha}^{-1}$ & $1276(796)$ & $228-4636$ \\
\hline
\end{tabular}

Note. $h_{\text {dom }}$ was calculated as the average height of the eight largest trees per plot $(n=40)$; DBH: Diameter at breast height.

\subsubsection{RS Data}

We used two sets of RS data in this study: Airborne LiDAR data and aerial imagery. Airborne LiDAR data were acquired in leaf-on conditions in September 2015 using an Optec Orion M300 sensor (Teledyne Technologies, Waterloo, ON, Canada) and were used to produce a digital terrain model (DTM) of the AOI. The average point density of LiDAR data was 11.67 points per $\mathrm{m}^{2}$, and 
the LiDAR points were classified as ground and non-ground by the data provider (Hokkaido Aero Asahi, Hokkaido, Japan). We used LiDAR ground points to develop a LiDAR terrain model with $1 \mathrm{~m}$ resolution $\left(\mathrm{DTM}_{\mathrm{LiDAR}}\right)$. The vertical height accuracy of $\mathrm{DTM}_{\mathrm{LiDAR}}$ was $0.13 \mathrm{~m} \mathrm{RMSE}_{\mathrm{Z}}$.

Aerial imagery was collected in June 2017 (leaf-on) and November 2017 (leaf-off) using a Trimble UX5 (Trimble Navigation, Sunnyvale, CA, USA) fixed-wing UAV platform. A Sony NEX-5 16.1-megapixel RGB camera (Sony, Tokyo, Japan) was mounted on the UAV. For each flight, we used camera settings that ensured the best exposure while preventing motion effects. The flight path was designed in the planning stage using Trimble Access Aerial Imaging (version 2.2.6). Flight altitude, flying speed, and longitudinal and lateral overlaps were set to $650 \mathrm{~m}, 80 \mathrm{~km} \mathrm{~h}^{-1}, 85 \%$, and $85 \%$, respectively. During each flight, the UAV took off, ascended to the predetermined flight altitude, flew the designed parallel track course, and returned to the launch site. The camera was triggered automatically according to a predefined flight plan, and the images were stored in jpeg format (8-bit unsigned images with an image resolution of $4912 \times 3264$ and a ground resolution of $14 \mathrm{~cm}$ ). The actual maximum flight time during our data acquisition was $\sim 25$ minutes per session: Thus, 4 flight sessions were required to complete the data acquisition over our AOI. After each flight session, the images were downloaded to a field laptop. Unwanted photos (e.g., photos taken during the takeoff and landing of the UAV and photos that were outside the study site) were trimmed, and the remaining images were used for the photogrammetric analysis.

\subsection{Processing of RS Data}

\subsubsection{Photogrammetric Processing}

First, we processed the leaf-on imagery. We used Agisoft PhotoScan Professional Edition 1.3.2 (Agisoft LLC, St. Petersburg, Russia) for a 3D reconstruction of the forest canopy. The in-built photogrammetric workflow of PhotoScan consists of two stages, image alignment and multiview stereopsis (MVS). Image alignment consists of sparse reconstruction of the 3D geometry by detection and matching of image feature points in overlapping images using a structure from motion (SfM) photogrammetric technique. In this stage, we used the highest image matching option (as our images were sharp enough for the highest setting), a key point limit of 40,000, and a tie point limit of 4000 . Absolute orientation was successful for all the input images. In order to optimize the image matching and to allow for more accurate georeferencing, we then optimized the camera orientation and internal parameters using 12 ground control points (GCPs). Optimization was conducted for the focal length in the $x$ and $y$ dimensions $\left(f_{x}, f_{y}\right)$, the principal point coordinates $(c x, c y)$, the radial distortion coefficients $\left(k_{1}, k_{2}, k_{3}\right)$, and the tangential distortion coefficients $\left(p_{1}, p_{2}\right)$. For leaf-on data, horizontal georeferencing accuracies of $0.14 \mathrm{~m} \mathrm{RMSE}_{\mathrm{X}}$ and $0.31 \mathrm{RMSE}_{Y}$ and a vertical accuracy of $1.03 \mathrm{~m} \mathrm{RMSE}_{Z}$ were achieved using GCPs. The second stage of processing is MVS, in which the software calculates depth information for images and combines all points into a single dense point cloud. PhotoScan offers 5 levels of "quality" (ultrahigh, high, medium, low, and lowest) in MVS. The ultrahigh quality setting processes the original images, while each lower level implies preliminary image size downscaling (using bilinear resampling) by a factor of 4 ( 2 times for each side). Although we tried to implement ultrahigh quality MVS, it could not be completed over the AOI due to excessive processing time and computer power requirements. Thus, to build the dense point cloud from aerial imagery, we used the remaining quality levels (high, medium, low, and lowest). This resulted in 4 separate dense point clouds for leaf-on imagery, as follows:

- Leaf-on P1: Built point cloud using downscaled images (original images by a factor of 4);

- Leaf-on P2: Built point cloud using downscaled images (original images by a factor of 16);

- Leaf-on P3: Built point cloud using downscaled images (original images by a factor of 64);

- Leaf-on P4: Built point cloud using downscaled images (original images by a factor of 256).

Mild depth filtering was applied for each point cloud to remove outliers and reduce noise. Except for the MVS "quality", none of the parameters were changed during photogrammetric processing to 
ensure consistency. Finally, the dense point clouds were exported in LAS format (Coordinate system: JGD2000 Japan-19 zone XII/GSIGEO 2000 geoid) for further processing. PhotoScan was installed on a workstation with an Intel Core i7-7700 CPU at 3.6 GHz, 64 GB RAM, 64-bit OS, and NVIDIA Quadro K2000 GPU.

\subsubsection{Development of CHMs and Extraction of Vegetation Metrics from Point Clouds and CHMs}

First, photogrammetric point clouds (leaf-on P1, leaf-on P2, leaf-on P3, and leaf-on P4) were used to develop digital surface models (DSMs). A grid $(0.3 \mathrm{~m}, 0.6 \mathrm{~m}, 1.2 \mathrm{~m}$, and $2.4 \mathrm{~m}$ for leaf-on P1, leaf-on P2, leaf-on P3, and leaf-on P4, respectively) was laid over the AOI. The maximum $z$ value of the point cloud within each grid cell was used as the DSM height for that grid cell. Then, by subtracting DTM $_{\text {LiDAR }}$ from the DSMs, we obtained the CHMs $\left(\mathrm{CHM}_{\text {leaf-onP1 }}, \mathrm{CHM}_{\text {leaf-onP2}}, \mathrm{CHM}_{\text {leaf-onP3 }}\right.$, and $\left.\mathrm{CHM}_{\text {leaf-onP4 }}\right)$.

Various vegetation metrics can be extracted from DAP products and used in forest attribute modeling: In particular, vegetation metrics extracted using either 3D point clouds or CHMs have been used frequently in previous studies, e.g., References [18,34,36,50,51]. Li et al. [41] showed that the model performance differed depending on whether LiDAR point cloud-derived metrics or CHM-derived metrics were used for aboveground biomass (AGB) modeling. Thus, in this study, we calculated vegetation metrics using both $\mathrm{CHMs}$ and point clouds. We calculated 4 plot-level vegetation metrics, e.g., $C H M_{\text {min }}, C H M_{\text {max }}, C H M_{\text {mean }}$, and $C_{\text {sd }}$ (Table 2), from the CHMs. We normalized the absolute heights of all the photogrammetric point clouds using DTM $\mathrm{LiDAR}_{\text {. Normalized }}$ point clouds were then used to extract the vegetation metrics (Table 2). With the freely available FUSION software package (version 3.60), 12 vegetation metrics were calculated for each sample plot $(n=52)$, with all points $>2 \mathrm{~m}$ height [52]. The vegetation metrics were selected on the basis of previous literature, e.g., References [18,20,34,53], that used DAP for forest structural attribute modeling.

The presence or absence of statistically significant differences between RS vegetation metric mean values of different point clouds was tested using one-way ANOVA. If the ANOVA test was significant, we computed "Tukey honest significant differences" (Tukey HSD) for performing multiple pairwise comparisons between the means of groups.

Table 2. Vegetation metrics used in this study. All metrics were calculated using a $>2-\mathrm{m}$ height threshold. CHM: Canopy height model.

\begin{tabular}{|c|c|c|}
\hline Data Source & Abbreviation & Description \\
\hline \multirow{9}{*}{ Point cloud-derived metrics } & $\mathrm{MinH}$ & The minimum height of all points within each plot \\
\hline & $\mathrm{MaxH}$ & The maximum height of all points within each plot \\
\hline & MeanH & The mean height of all points within each plot \\
\hline & $\mathrm{P} 10 \mathrm{H}, \mathrm{P} 25 \mathrm{H}, \mathrm{P} 50 \mathrm{H}, \mathrm{P} 75 \mathrm{H}$, and & 10th, 25th, 50th, 75th, and 95th percentile heights of all \\
\hline & $\mathrm{P} 95 \mathrm{H}$ & points within each plot \\
\hline & SDH & Standard deviation of point height within each plot \\
\hline & $\mathrm{CVH}$ & Coefficient of variation of point height within each plot \\
\hline & $D_{2 m}$ & $\begin{array}{l}\text { Proportion of points with }>2-m \text { height relative to the } \\
\text { total number of points }\end{array}$ \\
\hline & $D_{\text {mean }}$ & $\begin{array}{c}\text { Proportion of points with }>\text { mean height relative to the } \\
\text { total number of points }\end{array}$ \\
\hline \multirow{4}{*}{ CHM-derived metrics } & $\mathrm{CHM}_{\min }$ & The minimum value of all pixels within each plot \\
\hline & $\mathrm{CHM}_{\max }$ & The maximum value of all pixels within each plot \\
\hline & $\mathrm{CHM}_{\text {mean }}$ & The mean value of all pixels within each plot \\
\hline & $\mathrm{CHM}_{s d}$ & The standard deviation of all pixels within each plot \\
\hline
\end{tabular}

\subsection{Estimation of Forest Structural Attributes}

2.4.1. Leaf-On Aerial Imagery for Estimation of Forest Structural Attributes in Uneven-Aged Forests

When using high-resolution aerial imagery for building a 3D point cloud, photogrammetric software packages, such as PhotoScan, demand significant computing power. Thus, image downscaling (to reduce the original image resolution) is often carried out prior to building dense point clouds to speed up the processing and to reduce the computer power requirements. In our previous study [54], 
we observed that the downscaling of images tended to introduce some smoothing, as well as result in the unsuccessful reconstruction of fine peaks and isolated trees. Particularly, mixed forest stands were affected more by smoothing during the dense matching process (also noted by Reference [55]) and performed poorly in canopy roughness calculations. Probst et al. [56] compared the 3D reconstruction of vegetation using different MVS quality levels of PhotoScan and showed that there were differences in reconstruction. Nevertheless, they did not assess how such differences would affect forest attribute estimation. As different quality levels of PhotoScan downscale the original image resolution, a comparison of the potential of DAP products developed using different quality levels is also an assessment of the impact of image downscaling (as well as image resolution). On the basis of the results reported by previous studies [54-56], we hypothesized that image downscaling could affect forest attribute estimations. Thus, we compared the accuracy of height and biomass estimations using simple linear regression modeling (SLR) of vegetation metrics derived from leaf-on DAP point clouds (leaf-on P1-P4) and CHMs (CHM leaf-onP1-P4).

First, we used SLR because it is one of the most widely used methods in predicting forest attributes from ancillary data [12]. We tested the correlation between plot-level field structural attributes $\left(h_{d o m}\right.$, total biomass, conifer biomass, and broadleaf biomass) and vegetation metrics (point cloud-derived and CHM-derived). Then, we formed an SLR model using the vegetation metric that showed the strongest correlation with field-measured structural attributes (Equation (2)):

$$
Y=\alpha_{0}+\alpha X
$$

where $Y$ is the field-measured forest structural attribute $\left(h_{\text {dom }}\right.$, total biomass, conifer biomass, or broadleaf biomass), $\alpha_{0}$ and $\alpha$ are the regression coefficients, and $X$ is the vegetation metric that shows the strongest correlation with a particular forest structural attribute. Eight SLR models were produced for each attribute estimation (4 for point cloud-derived metrics to represent leaf-on P1-P4 and 4 for $\mathrm{CHM}$-derived metrics to represent $\left.\mathrm{CHM}_{\text {leaf-onP1-P4 }}\right)$. Then, we tested whether the accuracy of the biomass estimation could be further improved for uneven-aged forests by employing two of the most widely used modeling methods, i.e., multiple linear regression (MLR) and random forest (RF), which have been shown to improve the modeling accuracy of forest structural attributes, particularly biomass $[12,50,57,58]$, in less complex forest types.

In contrast to SLR, MLR uses more than one independent variable to predict the response variable. Many previous studies [18,34,51,59] have shown that linear multiple regression equations may be intrinsically linearized by transformation, e.g., that multiplicative models that are linear on the log scale perform better in forest attribute modeling, including biomass. Thus, we formulated a multiplicative model (Equation (3)) and then used ln transformation to simplify Equation (3) as a linear regression (Equation (4)):

$$
\begin{gathered}
Y=\beta_{0} X_{1}^{\beta 1} \ldots X_{n}^{\beta n}, \\
\ln Y=\ln \beta_{0}+\beta_{1} \ln X_{1}+\ldots+\beta_{n} \ln X_{n},
\end{gathered}
$$

where $Y$ is the field-measured biomass (total biomass or conifer biomass), $\beta_{0}, \beta_{1}, \ldots, \beta_{n}$ are the regression coefficients, $X_{1}, \ldots, X_{n}$ are the point cloud-derived vegetation metrics, and $n$ is the number of metrics. Stepwise variable selection was carried out, and the final model was selected according to Akaike's information criterion (AIC). In addition, the selection of predictor variables was penalized for collinearity using the variance inflation factor (VIF). When applying intrinsically linear multiple regression equations, adjustments are often necessary to correct the bias that occurs in the coefficient back transformation to the original scale [12]. Thus, we converted model predictions to an arithmetic scale and then multiplied by a bias correction factor, which was estimated as the ratio of the arithmetic sample mean and the mean of the back-transformed values predicted from the regression [60]. Version 3.5.0 of the R statistical software package [61] was used for SLR and MLR modeling. Leave-one-out cross-validation (LOOCV) was performed, and root-mean-square error (RMSE) and relative RMSE (\%RMSE) were calculated for model evaluation. 
$\mathrm{RF}$ is one of the most popular nonparametric machine learning techniques used in forestry applications [12]. RF is more popular than other tree-based regression models, as it is not subjected to overfitting and tends to be less biased [62,63]. Previous studies have had success using it to predict both area-based $[57,58]$ and individual tree-based structural attributes [64] using various RS data. RF is a decision tree algorithm that uses bootstrapping to select samples for model fitting. It combines predictions from a myriad of individual decision trees [12,62]. The decision trees are fully grown, and each is used to predict the observations that were not included in the bootstrap sample (also known as out-of-bag (OOB) observations). The average of many predictions determines the final prediction of an observation. The correlation between the trees and bias is often reduced in RF because only a small number of randomly selected predictor variables are used to find the best split at each node. We performed RF regression using the "randomForest" package of R statistical software [65] to estimate total biomass and conifer biomass at the plot level. The parameters mtry (i.e., the number of variables available for splitting at each node of the tree) and ntree (i.e., the number of trees adjusted to achieve a desirable prediction) were optimized to achieve the best model. All point cloud-derived variables (Table 2) were used to perform the initial RF run, and metrics were ranked on the basis of their predictive power (importance). The number of predictor variables in the model needs to be kept as low as possible to maintain model parsimony. Thus, variable selection was performed using a backward feature elimination method whereby the lowest performing variables were iteratively removed until the best model was obtained. The OOB error, which has previously been used as an unbiased estimate of the error, provides an internal leave-one-out cross-validation for RF modeling [41,63]. Thus, the best models for total biomass and conifer biomass were determined on the basis of the highest coefficient of determination $\left(R^{2}\right)$ and lowest RMSE estimated using OOB testing.

\subsubsection{Leaf-Off Aerial Imagery for Forest Attribute Estimation in Uneven-Aged Forests}

Leaf-off DAP data have been shown to be useful in tree species classification [66], terrain characterization [67], and individual tree detection [68]. Except for Bohlin et al. [42], who showed that leaf-off DAP data had a large impact on estimating deciduous forest attributes of well-managed conifer-dominated forests, leaf-off DAP has not been used for forest attribute estimation. This is particularly true for uneven-aged forests. Thus, in this study, we tested the potential of leaf-off aerial imagery for biomass estimation in uneven-aged forests. Photogrammetric processing was conducted using leaf-off aerial imagery following the procedures mentioned in Section 2.4.1. Nevertheless, only one point cloud was built using "high"-quality MVS, because the "high"-quality setting (downscaling the original imagery by a factor of 4) was determined to be an acceptable compromise between accuracy and computational time. Dense point clouds were used to extract vegetation metrics at the plot level. SLR, MLR, and RF regression models were established to estimate plot-level biomass. The results were then compared to leaf-on estimations of biomass.

\section{Results}

\subsection{Reconstruction of Canopy Surface and Derivation of Vegetation Metrics}

The processing time and point density of each quality level are summarized in Table 3. Leaf-on P1-the point cloud built from the images with the smallest downscaling factor (downscaling factor $=4$ ) — was the densest point cloud, whereas leaf-on P4, which was built from images downscaled by a factor of 256, was the sparsest point cloud. In addition, as expected, leaf-on P1 spent the longest time in the MVS process. 
Table 3. Processing time, point density, and original digital surface model (DSM) resolution of different quality levels using leaf-on aerial imagery.

\begin{tabular}{ccccc}
\hline & Leaf-On P1 & Leaf-On P2 & Leaf-On P3 & Leaf-On P4 \\
\hline Average point spacing $(\mathrm{m})$ & 0.18 & 0.41 & 0.96 & 2.10 \\
Maximum point spacing $(\mathrm{m})$ & 0.29 & 0.59 & 1.18 & 2.35 \\
Average point density $\left(\mathrm{m}^{-2}\right)$ & 11.5 & 3.1 & 0.72 & 0.18 \\
Time taken for building point cloud (hours) & $\sim 28$ & $\sim 15$ & $\sim 4$ & $\sim 2$ \\
DSM/CHM resolution $(\mathrm{m})$ & 0.30 & 0.60 & 1.2 & 2.4 \\
\hline
\end{tabular}

$\mathrm{CHM}_{\text {leaf-onP4 }}$ showed the highest level of the smoothing effect, whereas the effect of smoothing was reduced when the image downscaling factor decreased (Figure 2). It was difficult to clearly identify individual tree crowns in $\mathrm{CHM}_{\text {leaf-onP3 }}$ and $\mathrm{CHM}_{\text {leaf-onP4 }}$. In $\mathrm{CHM}_{\text {leaf-onP2, }}$, the individual tree crowns were generally wider and less defined compared to those in $\mathrm{CHM}_{\text {leaf-onP1 }}$. In addition, the small canopy gaps were better represented in $\mathrm{CHM}_{\text {leaf-onP1 }}$. These trends could be observed in young forest stands, as well as in conifer-dominated mature and broadleaf-dominated mature forest stands.

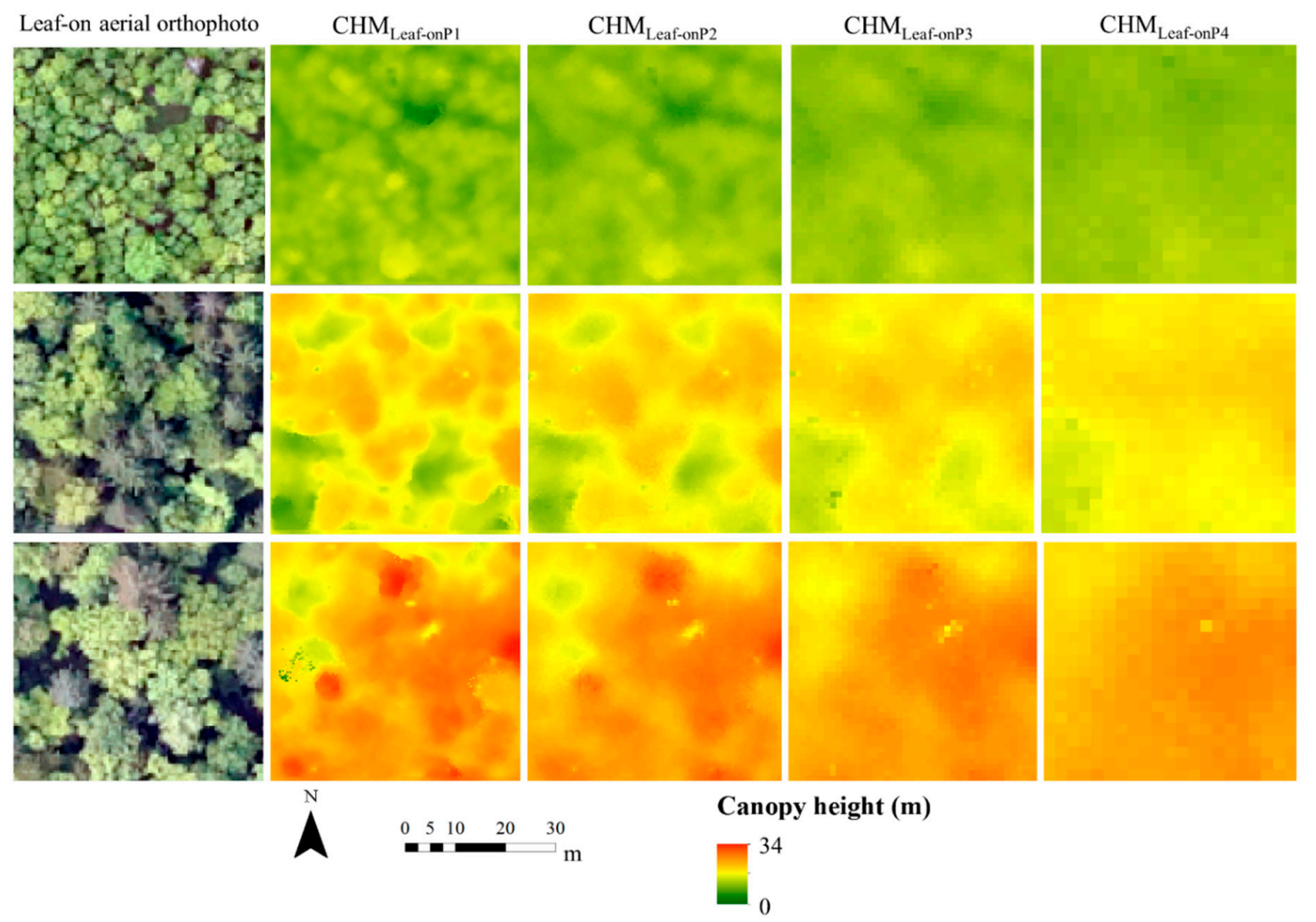

Figure 2. Plot-level CHMs produced using leaf-on DAP. Representative sample plots of young (upper panel), conifer-dominated mature (middle panel), and broadleaf-dominated mature (lower panel) stands are presented. An aerial orthophoto ( $0.5 \mathrm{~m}$ resolution) for each sample plot is also shown for reference. The resolution of $\mathrm{CHM}_{\text {leaf-onP1 }}, \mathrm{CHM}_{\text {leaf-onP2 }}, \mathrm{CHM}_{\text {leaf-onP3 }}$, and $\mathrm{CHM}_{\text {leaf-onP4 }}$ is $0.3 \mathrm{~m}, 0.6 \mathrm{~m}$, $1.2 \mathrm{~m}$, and $2.4 \mathrm{~m}$, respectively.

Comparisons of point cloud- and CHM-derived vegetation metrics among different point clouds (leaf-on P1-P4) are provided in Figure 3. MeanH, P25H, P50H, P75H, P95H, $D_{\text {mean }}$, and $\mathrm{CHM}_{\text {mean }}$ were not significantly different $(p<0.05)$ among the point clouds and CHMs produced from the downscaled images. Point density above vegetation height $\left(D_{2 m}\right)$, some height metrics $(\operatorname{MinH}, \operatorname{MaxH}$, $\mathrm{P1OH}, \mathrm{CHM}_{\min }$, and $\mathrm{CHM}_{\max }$ ), and all height variation metrics $\left(\mathrm{SDH}, \mathrm{CVH}, \mathrm{CHM}_{s d}\right.$ ) showed statistically significant differences $(p<0.05)$ among the point clouds and CHMs produced from the downscaled 
images. Overall, none of the point cloud-derived vegetation metrics showed statistically significant differences between leaf-on P1 and leaf-on P2, while two CHM-derived metrics, i.e., $\mathrm{CHM}_{\text {min }}$ and $C H M_{s d}$, showed statistically significant differences $(p<0.05)$ between leaf-on P1 and leaf-on P2 (Figure $3 \mathrm{~m}, \mathrm{p}$ ). In contrast, most of the vegetation metrics were significantly different between leaf-on P1 and P4, leaf-on P2 and P4, leaf-on P1 and P3, and leaf-on P3 and P4.
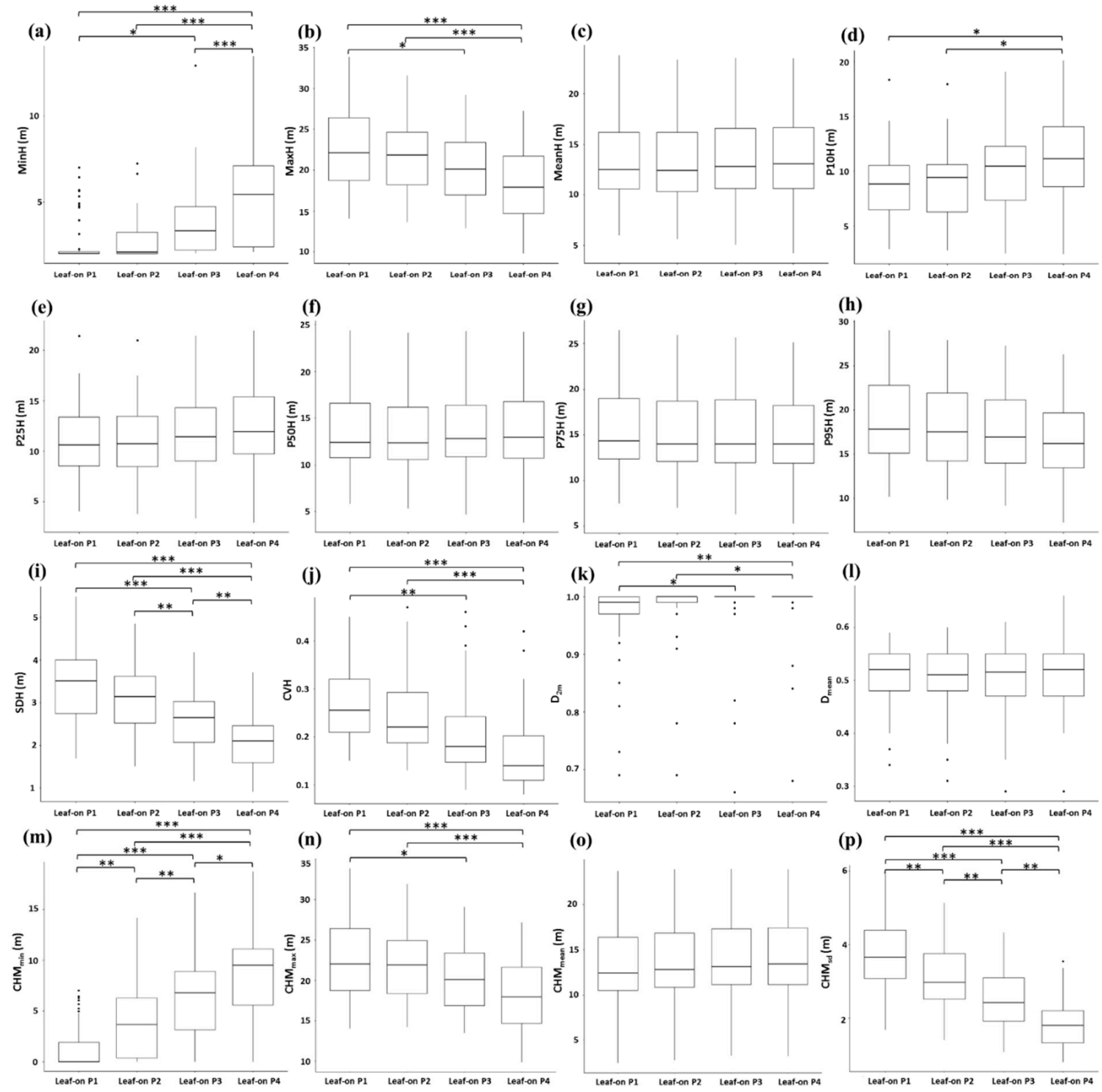

Figure 3. Comparison of plot-level point cloud-derived vegetation metrics (a-1) and CHM-derived vegetation metrics $(\mathbf{m}-\mathbf{p}) ; p>0.05$ where it is not specifically shown. Significance codes: ${ }^{* *} p<0.001$, ** $p<0.01, p<0.05$.

\subsection{Estimation of Plot-Level Forest Structural Attributes}

3.2.1. Comparison of the Accuracy of Height and Biomass Estimation Using SLR Modeling for Different Image Downscaling Levels

The $\mathrm{P} 95 \mathrm{H}$ vegetation metric showed the strongest correlation with field-measured total biomass $(R$ values of $0.89,0.88,0.87$, and 0.86 for leaf-on P1, P2, P3, and P4, respectively, $p<0.0001$ ) and broadleaf biomass ( $R$ values of $0.62,0.64,0.66$, and 0.66 for leaf-on P1, P2, P3, and P4, respectively, $p<0.001$ ). The $\mathrm{P} 75 \mathrm{H}$ height showed the strongest correlation with both $h_{\text {dom }}(R=0.94$ for leaf-on P1 and P2, and $R=0.93$ leaf-on P3 and P4, $p<0.0001)$ and conifer biomass $(R$ values of $0.79,0.77,0.75$, and 0.73 for 
leaf-on P1, P2, P3, and P4, respectively, $p<0.0001)$. $C H M_{\max }$ showed the highest correlation with $h_{\text {dom }}$ $\left(R=0.91\right.$ for $\mathrm{CHM}_{\text {leaf-onP4 }}$ and $R=0.92$ for $\left.\mathrm{CHM}_{\text {leaf-onP1-P3, }} p>0.0001\right)$ and total biomass $(R$ values of $0.87,0.86,0.84$, and 0.84 for $\mathrm{CHM}_{\text {leaf-onP1 }}, \mathrm{CHM}_{\text {leaf-onP2 }}, \mathrm{CHM}_{\text {leaf-onP3 }}$, and $\mathrm{CHM}_{\text {leaf-onP4 }}, p>0.0001$ ). Conifer biomass ( $R$ values of $0.74,0.74,0.73$, and 0.72 for $\mathrm{CHM}_{\text {leaf-onP1 }}, \mathrm{CHM}_{\text {leaf-onP2}}, \mathrm{CHM}_{\text {leaf-onP3, }}$, and $\mathrm{CHM}_{\text {leaf-onP4, }}$, respectively, $p>0.0001$ ) and broadleaf biomass showed a strong correlation with $\mathrm{CHM}_{\text {mean }}$ $\left(R=0.59\right.$ for $\mathrm{CHM}_{\text {leaf-onP1 }}$ and $\mathrm{CHM}_{\text {leaf-onP2 }}, R=0.60$ for $\mathrm{CHM}_{\text {leaf-onP3 }}$ and 0.61 for $\mathrm{CHM}_{\text {leaf-onP1, }}$, $p>0.001)$.

For the SLR models of $h_{\text {dom }}$, total biomass, and conifer biomass (using point cloud-derived vegetation metrics), the highest $R^{2}$ and the lowest \%RMSE were observed for leaf-on P1, which was the point cloud built from the lowest factor of downscaling (Table 4 and Figure 4). When the downscaling factor increased, the $R^{2}$ values decreased while the \%RMSE values increased (Table 4). In contrast, \%RMSE of broadleaf biomass estimation decreased with the increase in the image downscaling factor. We observed similar trends when using CHM-derived vegetation metrics as well (Table 5). However, except for broadleaf biomass, the \%RMSE values obtained for models that included CHM-derived vegetation metrics were higher compared to the models that included point cloud-derived vegetation metrics (Tables 4 and 5). Overall, the $h_{\text {dom }}$ prediction performed best for all point clouds using both point cloud-derived and CHM-derived metrics, and the results of total biomass predictions were acceptable. Nevertheless, SLR performed relatively poorly in estimating conifer biomass and broadleaf biomass.

Table 4. Results of simple linear regression (SLR) using point cloud-derived vegetation metrics for $h_{\text {dom }}$ $(n=40)$, total biomass $(n=52)$, conifer biomass $(n=52)$, and broadleaf biomass $(n=52)$ estimation.

\begin{tabular}{cccccccccc}
\hline \multirow{2}{*}{ Forest Structural Attribute } & \multirow{2}{*}{ Explanatory Variable } & \multicolumn{2}{c}{ Leaf-On P1 } & \multicolumn{2}{c}{ Leaf-On P2 } & \multicolumn{2}{c}{ Leaf-On P3 } & \multicolumn{2}{c}{ Leaf-On P4 } \\
\cline { 3 - 9 } & & $\boldsymbol{R}^{\mathbf{2}}$ & $\mathbf{\% R M S E}$ & $\boldsymbol{R}^{\mathbf{2}}$ & \%RMSE & $\boldsymbol{R}^{\mathbf{2}}$ & \%RMSE & $\boldsymbol{R}^{\mathbf{2}}$ & \%RMSE \\
\hline$h_{\text {dom }}$ & $P 75$ & 0.88 & 6.4 & 0.88 & 6.6 & 0.87 & 6.9 & 0.86 & 7.0 \\
Total biomass & $P 95$ & 0.78 & 21.1 & 0.77 & 21.7 & 0.76 & 22.3 & 0.74 & 23.4 \\
Conifer biomass & $P 75$ & 0.62 & 63.8 & 0.60 & 64.8 & 0.57 & 67.0 & 0.53 & 69.7 \\
Broadleaf biomass & P95 & 0.39 & 33.2 & 0.42 & 29.7 & 0.43 & 31.1 & 0.43 & 29.2 \\
\hline
\end{tabular}

Table 5. Results of SLR using CHM-derived vegetation metrics for $h_{\text {dom }}(n=40)$, total biomass $(n=52)$, conifer biomass $(n=52)$, and broadleaf biomass $(n=52)$ estimation.

\begin{tabular}{|c|c|c|c|c|c|c|c|c|c|}
\hline \multirow{2}{*}{ Forest Structural Attribute } & \multirow{2}{*}{ Explanatory Variable } & \multicolumn{2}{|c|}{ Leaf-On P1 } & \multicolumn{2}{|c|}{ Leaf-On P2 } & \multicolumn{2}{|c|}{ Leaf-On P3 } & \multicolumn{2}{|c|}{ Leaf-On P4 } \\
\hline & & $R^{2}$ & \%RMSE & $R^{2}$ & \%RMSE & $R^{2}$ & $\%$ RMSE & $R^{2}$ & $\%$ RMSE \\
\hline$h_{\text {dom }}$ & $\mathrm{CHM}_{\max }$ & 0.83 & 7.7 & 0.80 & 8.3 & 0.78 & 8.7 & 0.75 & 9.3 \\
\hline Total biomass & $C H M_{\max }$ & 0.76 & 22.8 & 0.74 & 23.6 & 0.71 & 24.8 & 0.71 & 24.9 \\
\hline Conifer biomass & $\mathrm{CHM}_{\text {mean }}$ & 0.54 & 68.9 & 0.54 & 68.9 & 0.53 & 69.8 & 0.52 & 70.4 \\
\hline Broadleaf biomass & $\mathrm{CHM}_{\text {mean }}$ & 0.35 & 31.4 & 0.35 & 31.2 & 0.36 & 31.1 & 0.37 & 30.8 \\
\hline
\end{tabular}


(a)

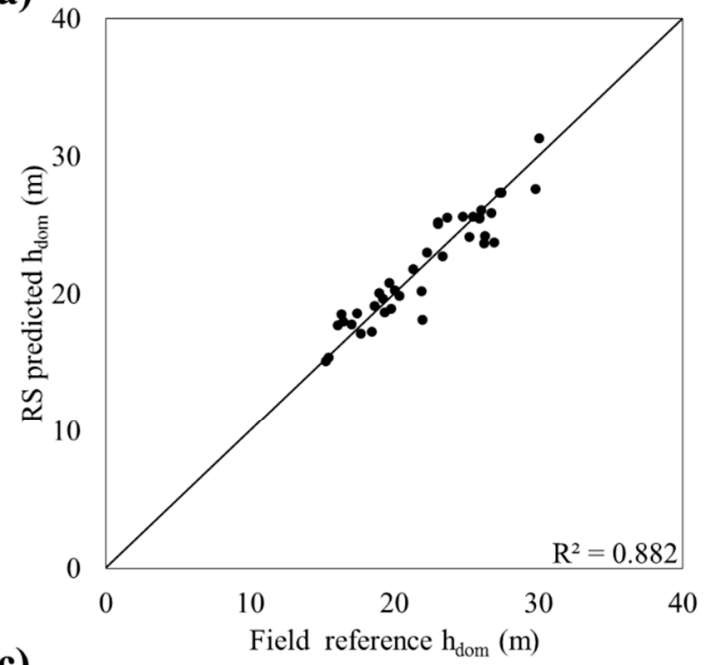

(c)

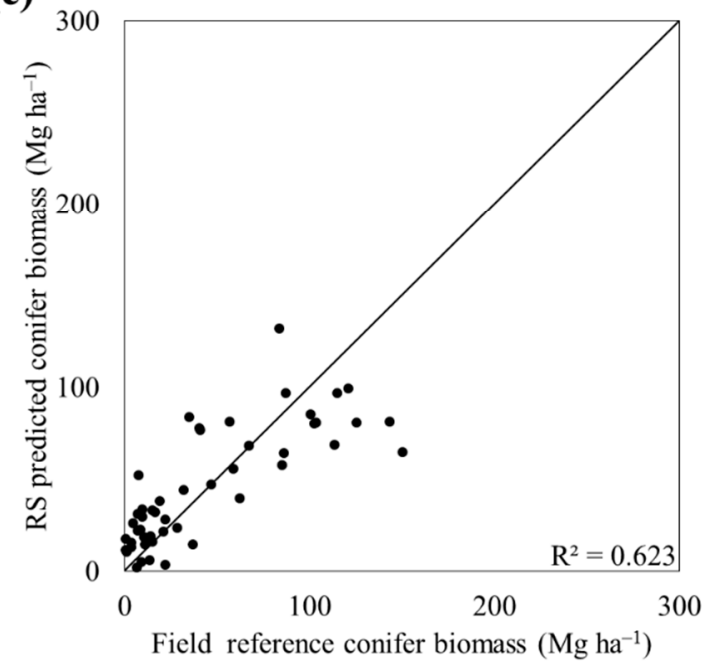

(b)

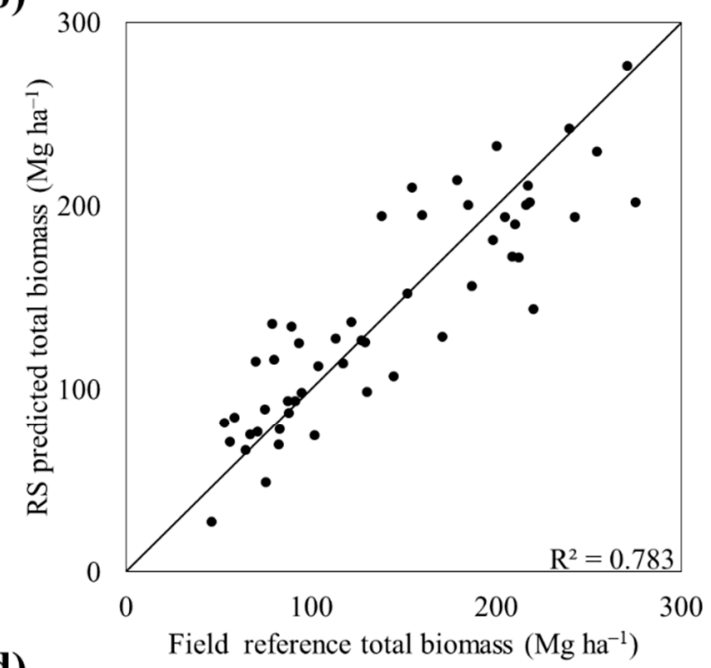

(d)

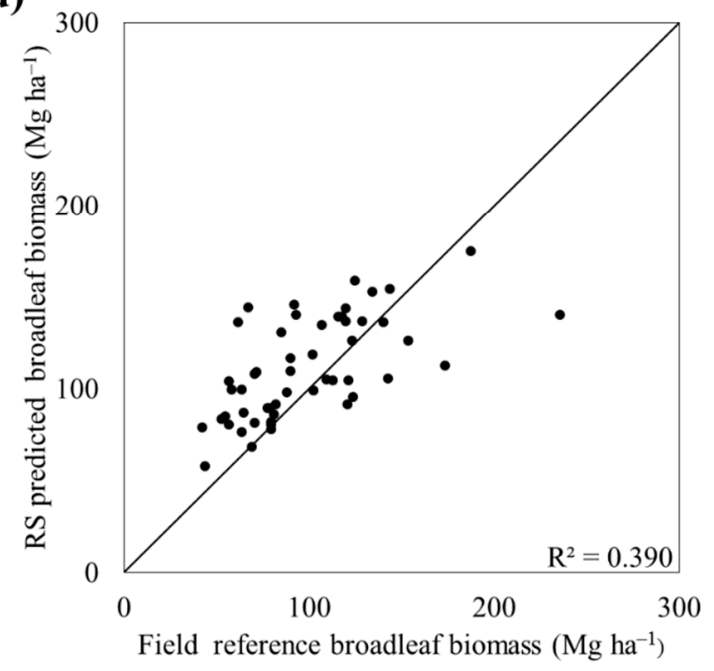

Figure 4. Scatterplots of field reference and SLR-estimated $h_{\text {dom }}(\mathbf{a})$, total biomass $(\mathbf{b})$, conifer biomass $(\mathbf{c})$, and broadleaf biomass (d). $n=52$ for total and conifer biomass, whereas $n=40$ for $h_{\text {dom }}$. Vegetation metrics derived from leaf-on P1 were used in SLR modeling.

\subsubsection{Comparison of the Model Performance in Biomass Estimation}

The MLR model of total biomass included $P 75 H$ and $D_{\text {mean }}$ as predictor variables, whereas the MLR model of conifer biomass included $M e a n H, S D H$, and $D_{\text {mean }}$ as predictor variables. The optimal MLR model of broadleaf biomass included $P 95 \mathrm{H}$ and $S D H$ as predictor variables. In comparison to SLR, the MLR model produced better predictions of total biomass $\left(R^{2}=0.85, \%\right.$ RMSE $\left.=18.1\right)$, conifer biomass $\left(R^{2}=0.66, \%\right.$ RMSE $\left.=63.6\right)$, and broadleaf biomass $\left(R^{2}=0.57, \%\right.$ RMSE $\left.=26.3\right)($ Table 6 and Figure $5 \mathrm{a}-\mathrm{c})$.

Table 6. Results of SLR, MLR, and RF models using point cloud-derived vegetation metrics for biomass estimation. Vegetation metrics extracted from leaf-on P1 were used for modeling $(n=52)$.

\begin{tabular}{ccccccc}
\hline \multirow{2}{*}{ Forest Structural Attribute } & \multicolumn{2}{c}{ SLR } & \multicolumn{2}{c}{ MLR } & \multicolumn{2}{c}{ RF } \\
\cline { 2 - 7 } & $\boldsymbol{R}^{\mathbf{2}}$ & \%RMSE & $\boldsymbol{R}^{\mathbf{2}}$ & \%RMSE & $\boldsymbol{R}^{\mathbf{2}}$ & \%RMSE \\
\hline Total biomass & 0.78 & 21.1 & 0.85 & 18.1 & 0.94 & 12.0 \\
Conifer biomass & 0.62 & 63.8 & 0.66 & 60.5 & 0.90 & 32.1 \\
Broadleaf biomass & 0.39 & 33.2 & 0.57 & 26.3 & 0.87 & 22.7 \\
\hline
\end{tabular}


(a)

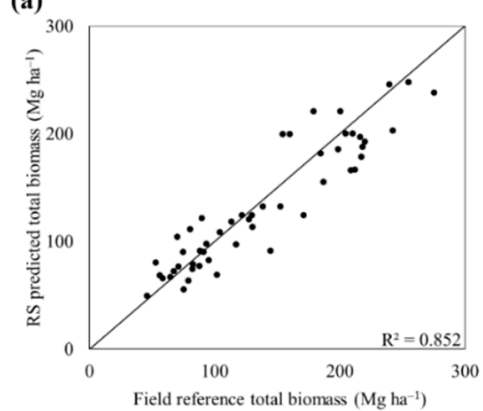

(d)

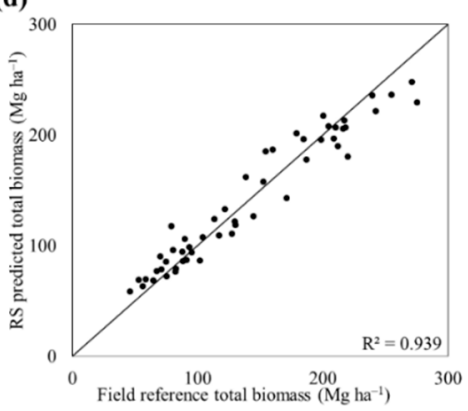

(b)

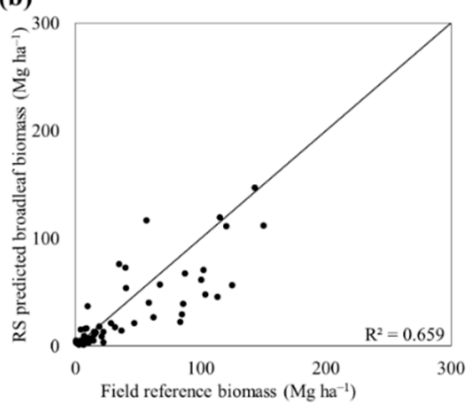

(e)

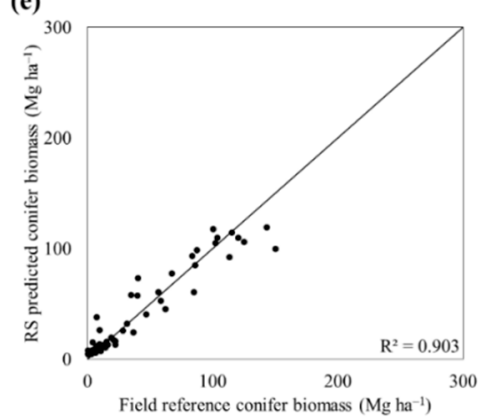

(c)

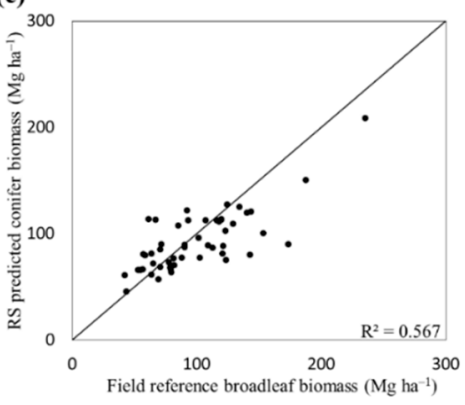

(f)

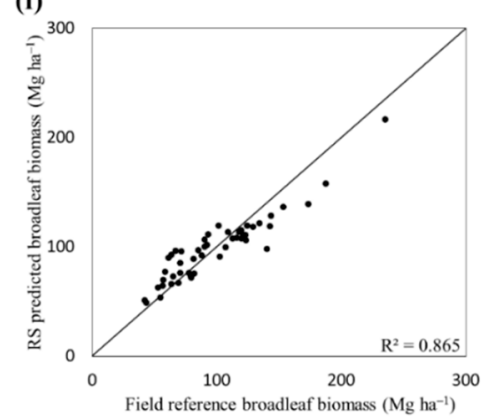

Figure 5. Scatterplots of field reference and multiple linear regression (MLR) (a-c) and random forest $(\mathrm{RF})(\mathbf{d}-\mathbf{f})$ model predicted biomass $(n=52)$ using point cloud-derived (leaf-on P1) metrics.

Variable selection retained $P 95 H, P 75 H, M a x H, M e a n H$, and $S D H$ in the final RF model of total biomass, whereas the RF model of conifer biomass included $\mathrm{P75H}, \mathrm{MeanH}, \mathrm{P95H}, \mathrm{P10H}, \mathrm{P} 50 \mathrm{H}$, and $\mathrm{P2} 2 \mathrm{H}$. Further, compared to SLR and MLR, the optimal RF model significantly improved the total, conifer, and broadleaf biomass prediction accuracies (Table 6). Although low biomass values were overestimated and high biomass values were overestimated in the RF model, the scatterplot shows an overall good fit between the field reference and RF predicted total biomass (Figure $5 \mathrm{~d}-\mathrm{f}$ ).

\subsubsection{Leaf-Off DAP for Biomass Estimation}

In the leaf-off 3D point cloud, the points were concentrated mainly in areas where evergreen vegetation was present. Deciduous crowns were not reconstructed, and the points were generated on the ground in those areas. Vegetation metrics could not be calculated for four plots that were established in the high-altitude reserve forest areas (low tree density and mostly deciduous species were present) and three plots that were established in the young broadleaf stands (only deciduous species were present, and thus conifer biomass $<5 \mathrm{Mg} \mathrm{ha}^{-1}$ ) because those plots did not contain any points for which height $>2 \mathrm{~m}$. Thus, those seven plots were excluded from the analysis. In the SLR model, leaf-off DAP $\left(R^{2}=0.63\right.$ and \%RMSE $\left.=10.4\right)$ performed relatively poorly for $h_{\text {dom }}$ estimation in comparison to leaf-on DAP $\left(R^{2}=0.88\right.$ and \%RMSE $\left.=6.4\right)$.

MaxH showed the strongest correlation with total biomass $(0.83, p<0.0001)$ and conifer biomass $(0.78$, $p<0.0001)$, whereas $\mathrm{P95H}$ showed the strongest correlation with broadleaf biomass $(0.53, p<0.001)$. Total biomass estimation using leaf-on DAP (Table 6) performed better than leaf-off DAP (Table 7) with SLR modeling ( $\%$ RMSE $=21.1$ and $\%$ RMSE $=23.1 \%$ for leaf-on and leaf-off DAP, respectively). Nevertheless, leaf-off DAP $\left(R^{2}=0.64\right.$ and \%RMSE $\left.=56.3\right)$ performed slightly better for conifer biomass estimation using SLR modeling. The performance of broadleaf biomass estimation was negatively affected (\%RMSE increased from 33.2 to 56.7 using SLR modeling) by leaf-off DAP. Similar to leaf-on DAP, biomass prediction accuracies were slightly improved by MLR modeling with leaf-off DAP. RF produced better biomass estimations using leaf-off DAP-derived vegetation metrics as well (Table 7 and Figure 6). Overall, RF performed better in total and broadleaf biomass estimation using leaf-on DAP (\%RMSEs of 12.0 and 22.7 for total and broadleaf, respectively) compared to leaf-off DAP (\%RMSEs of 15.0 and 
35.5 for total and broadleaf, respectively), while conifer biomass estimation was better using leaf-off DAP $(\%$ RMSE $=32.1$ for leaf-on and \%RMSE $=23.8$ for leaf-off $)$.
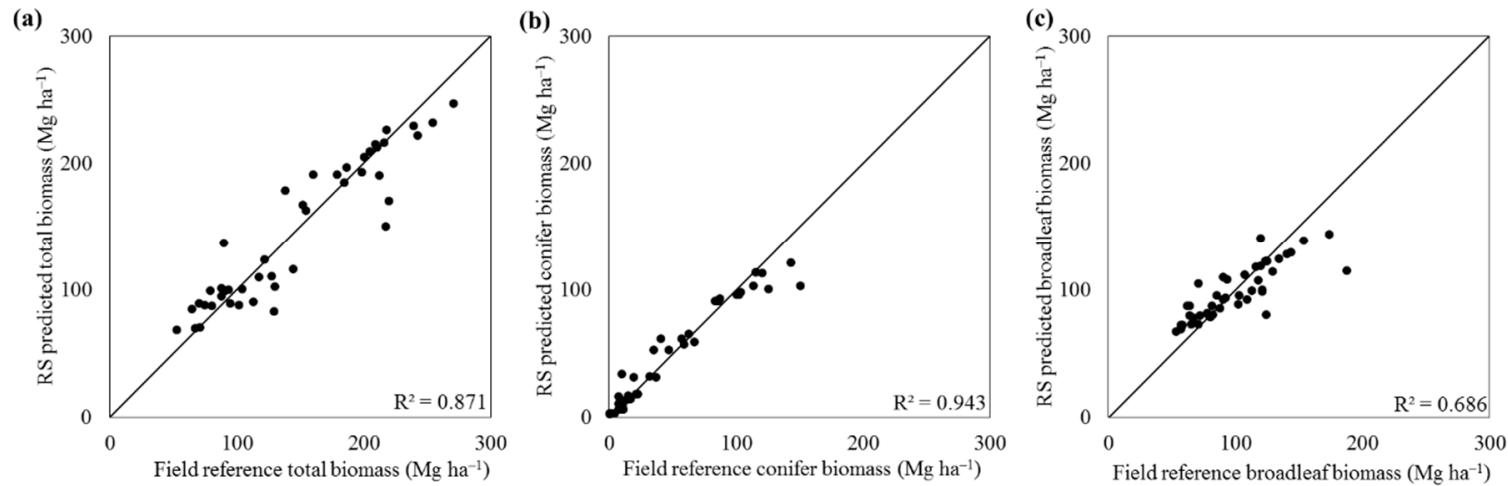

Figure 6. Scatterplots of field reference and RF estimated total biomass (a), conifer biomass (b) and broadleaf biomass (c) using leaf-off point cloud-derived metrics $(n=45)$.

Table 7. Results of SLR, MLR, and RF modeling using point cloud-derived vegetation metrics for biomass estimation. Vegetation metrics that were extracted from leaf-off point clouds were used for modeling $(n=45)$.

\begin{tabular}{ccccccc}
\hline \multirow{2}{*}{ Forest Structural Attribute } & \multicolumn{2}{c}{ SLR } & \multicolumn{2}{c}{ MLR } & \multicolumn{2}{c}{ RF } \\
\cline { 2 - 7 } & $\boldsymbol{R}^{\mathbf{2}}$ & \%RMSE & $\boldsymbol{R}^{\mathbf{2}}$ & \%RMSE & $\boldsymbol{R}^{\mathbf{2}}$ & \%RMSE \\
\hline Total biomass & 0.70 & 23.1 & 0.72 & 22.2 & 0.87 & 15.0 \\
Conifer biomass & 0.64 & 56.3 & 0.71 & 53.2 & 0.94 & 23.8 \\
Broadleaf biomass & 0.28 & 56.7 & 0.30 & 48.3 & 0.69 & 35.5 \\
\hline
\end{tabular}

\section{Discussion}

This study aimed to examine the potential for leaf-on and leaf-off DAP to act as a complementary data source for the assessment of uneven-aged forest resources. Some promising results were produced.

\subsection{Reconstruction of 3D Forest Structure Using DAP}

DAP is capable of providing information about 3D forest structure [16]: Thus, it has emerged as an alternative to high-cost airborne laser scanning (ALS). However, it is important to note that DAP and ALS are two fundamentally different techniques that characterize the forest structure differently. ALS is an active RS technique that uses laser pulses capable of penetrating the canopy layer, whereas DAP indirectly reconstructs the 3D forest structure using optical aerial imagery. Unlike ALS, which facilitates the characterization of the horizontal canopy structure, vertical vegetation profile, and terrain, DAP mostly represents the variation in the upper components of the forest structure, such as dominant and codominant tree crowns in the forest canopy [69]. Also, DAP often does not perform adequately when characterizing below-canopy vegetation or terrain in dense forest areas $[54,55]$.

The accurate and detailed reconstruction of 3D structures by DAP greatly depends on various image-related factors, including overall quality, overlapping, image resolution, sharpness, and occlusions $[31,54,55,70,71]$. Thus, it is important to understand the impact of such factors on the characterization of forest structure, particularly on forest attribute estimation. In this study, we focused on the impact of image resolution on DAP for an uneven-aged mixed conifer-broadleaf forest.

Our results demonstrated that image downscaling had a negative impact on point density and spacing (Table 4), CHM (Figure 2), and CHM- and point cloud-derived vegetation metrics (Figure 3). $\mathrm{CHM}$ was greatly affected by smoothing if the downscaling factor was relatively large, e.g., 64 and 256. The individual tree crowns were less defined in CHMs produced from low-resolution images (largely downscaled images), e.g., $\mathrm{CHM}_{\text {leaf-onP3 }}$ and $\mathrm{CHM}_{\text {leaf-onP4 }}$ (Figure 2). In our previous 
study [54], we observed that mixed forest stands were more prone to smoothing than broadleaf stands. Lisein et al. [55] reported similar results in their study. Thus, the smoothing effect on CHM could affect the delineation of individual tree crowns in uneven-aged mixed stands. Several commonly used vegetation height metrics in forestry applications, such as higher height percentiles $(P 95, P 75)$ and mean canopy height (denoted by MeanH in this study), did not show statistically significant differences between point clouds (Figure 3). Conversely, the vegetation metrics that explained the vertical variation in the canopy $\left(S D H, C V H, C H M_{s d}\right)$ showed statistically significant differences between point clouds (Figure 3). Nevertheless, it should be noted that the plot size might have had some impact on this result: For instance, smaller plot sizes than ours may not be appropriate to describe the vegetation height nor the height variations if the point density is too low (similar to leaf-on P4 in this study). In brief, the downscaling of images resulted in smoothing the CHMs and affected the measures of canopy roughness. Thus, we claim that image resolution could play an important role when analyzing forest canopy structural complexity using DAP over uneven-aged forests that have complex structural and spatial variations.

\subsection{Leaf-On DAP for Biomass Estimation in Uneven-Aged Forests}

In this study, we report several important findings on biomass estimation in uneven-aged forests.

First, the accuracy of total biomass estimation did not significantly change with image resolution. This was mainly due to the fact that the optimal SLR models of total biomass included the higher height percentiles, e.g., $\mathrm{P} 95 \mathrm{H}$ and $\mathrm{P} 75 \mathrm{H}$, which did not show significant differences between point clouds (leaf-on P1-P4) at the plot level (Figure 3). Therefore, it could be argued that the use of very high-resolution imagery with a relatively small downscaling factor for DAP could facilitate acceptable estimations of total woody biomass in uneven-aged forests while saving processing time and computer power.

Second, both point cloud-derived and CHM-derived metrics were capable of providing acceptable results for total biomass estimation (Tables 4 and 5). This result is consistent with Ota et al. [50], who reported high accuracy (Adj. $R^{2}=0.93$ ) for AGB estimation using DAP CHM-derived metrics in a less complex seasonal tropical forest in Cambodia using SLR modeling. However, it is important to note that the accuracy was slightly better in our study when point cloud-derived metrics were used for estimating total biomass. This may have been due to the consideration of fine variations in point heights when calculating vegetation metrics using point cloud data. For instance, when developing a CHM, we only chose the maximum height point in a grid cell: Consequently, we considered only those selected point values when deriving plot-level CHM metrics. However, when calculating the vegetation metrics using point clouds, we included all the points within a plot, thus considering the fine height variations in all the points.

Third, SLR, being one of the simplest modeling techniques, produced acceptable results for total biomass estimations (Table 6 and Figure 4a) in uneven-aged forests, but the accuracy could be further improved (Table 6 and Figure 5a) when additional explanatory variables were introduced into the regression modeling (e.g., MLR). In less complex forest types (e.g., Reference [50]), such as even-aged, woodland, or sparse forests, where most of the individual trees reach the canopy, the canopy height variables are strongly correlated with biomass: Hence, even a single height variable is capable of explaining most of the variation in the total woody biomass. In contrast, uneven-aged forests comprise trees at different growth stages with a range of height stratifications: Thus, these types of forests often have complex spatial and structural variations that make it difficult for only one height variable to explain most of the variation in the total biomass. Thus, the use of MLR to include more than one explanatory variable in the regression model could provide additional explanatory power and result in lower \%RMSE than SLR in uneven-aged forests.

Fourth, the total biomass estimation accuracies were significantly improved by RF modeling (Table 6 and Figure 5d). As a nonparametric method, RF has no formal distribution assumptions, allows nonlinear variable relationships, is relatively unaffected by multicollinearity and outliers, estimates 
variable importance from cross-validation, and handles variable interactions without pre-specification [62]. The better performance of RF is comparable to studies by previous authors $[41,57,58]$ who showed that RF modeling is superior for biomass modeling for a range of forest types, including uneven-aged forests, with different types of RS data. The improved performance of RF could be attributed to the inclusion of a modest number of extreme values in the reference dataset, the tuning of the model for optimal parameters, and the variable selection that was conducted on the basis of variable importance. If the vegetation metrics represent interactions that are too complex to be captured by parametric regression models, the RF model fits more appropriately because the biomass in complex forests is not controlled simply by one or two driving variables but a complex environment [41], e.g., uneven-aged forest environments. However, it is important to understand that RF is associated with some limitations: (1) The RF model constrains the predicted biomass within the range of observed biomass values, and thus sampling should be conducted carefully to include a modest number of extreme values [36,41]; (2) understanding the computation of RF is difficult due to the complexity of the RF algorithm [72].

Finally, both conifer and broadleaf biomass estimations using linear regression (SLR and MLR) performed poorly (Table 4, Figure 4c,d, Figure $5 b, c$ ) for all the point clouds, as well as for all CHMs. This could be attributed to the forest structure and the vegetation metrics used in this study. The height and density metrics we calculated in this study represented the overall forest structure and did not provide any specific information about conifer or broadleaf biomass. Consequently, such vegetation metrics did not show a strong linear relationship with conifer or broadleaf biomass and were not capable of adequately explaining the variation in species-specific biomass. The accuracy might improve if vegetation metrics that could specifically describe vegetation composition are included in the modeling. Nevertheless, due to the dense canopy cover and highly overlapping crowns, it could be difficult to calculate such metrics in uneven-aged forest resources. The accuracy of conifer and broadleaf biomass estimations was significantly improved when RF modeling was applied (Figure 5e,f). As discussed in the previous paragraph, as a nonparametric method, the RF model might have the potential to estimate conifer and broadleaf biomass in complex forests considering the complex relationships between biomass and vegetation metrics. However, the complexity of the RF algorithm makes it difficult to understand the exact reason behind the improved accuracy of conifer and broadleaf biomass estimation. We could not compare our results to those of previous studies due to the lack of projects that have used DAP for conifer or broadleaf biomass estimation in uneven-aged forests. Thus, future research into species-specific forest inventory using DAP and RF in uneven-aged forests might provide new insights.

\subsection{Leaf-Off DAP for Biomass Estimation over Uneven-Aged Forests}

In the 3D forest structure reconstruction using leaf-off data, the canopy area that was mainly composed of deciduous species was not reconstructed in the DAP point cloud, whereas the conifer-dominated canopy areas were well reconstructed. Species distribution (evergreen and deciduous) at the canopy level, as well as image resolution, might be the reason for these unconstructed areas. Contradictory to our findings, some previous studies $[68,73,74]$ could reconstruct the vegetation and estimate forest structural attributes (e.g., height and $\mathrm{DBH}$ ), perhaps due to a higher aerial image resolution than that used in our study. As expected, leaf-on DAP performed better in comparison to leaf-off DAP in terms of total and broadleaf biomass estimations over the AOI (Tables 6 and 7), particularly when using SLR and MLR modeling. Similar observations were reported by Bohlin et al. [42,75] for volume estimation in well-managed mixed forests. Although we expected to obtain improved results for conifer biomass estimation using leaf-off DAP, regression modeling accuracies of leaf-off DAP did not significantly improve compared to those of leaf-on DAP (Tables 6 and 7). The negative impact of leaf-off DAP on forest attribute estimation, which was noted by Bohlin et al. [42,75] in well-managed forests for volume estimation, was further confirmed by the results of this study. Unconstructed leaf-off trees, which resulted in the underestimation of canopy height metrics, could be the reason for the relatively poor performance of leaf-off DAP in biomass estimation, particularly in young broadleaf stands and broadleaf-dominated stands (Table 7). 
On the other hand, RF performed well with leaf-off DAP data for biomass estimation (Table 7 and Figure 6). Specifically, the conifer and broadleaf biomass estimations were significantly improved. The improved accuracy could be partly attributed to the predictor variables that were included in the RF model, and, as such, the RF model included predictor variables on the basis of their importance. As discussed in the previous section, the RF model might have captured complex interactions between biomass and RS vegetation metrics that were too complex to capture with the linear regression models. Therefore, it could be said that both the data source and statistical method play important roles in accurate biomass estimation. Although leaf-off DAP for a mixed conifer-broadleaf forest area did not perform as well as leaf-on data in biomass estimation, it could be useful for DTM generation, as a considerable portion of the points were constructed on the ground [76].

\section{Conclusions}

In this study, we tested the utility of leaf-on and leaf-off DAP coupled with field training data to estimate biomass over an uneven-aged mixed conifer-broadleaf forest in northern Japan. We demonstrated that image downscaling had a negative impact on the point density, CHM, and the vegetation metrics that explain height variation, e.g., $\mathrm{SDH}, \mathrm{CVH}, \mathrm{CHM}_{s d}$. Specifically, image downscaling introduced a smoothing effect to the canopy reconstruction that resulted in a smoothed $\mathrm{CHM}$ with less-defined individual tree crowns. In addition, image downscaling affected the measures of canopy roughness and vertical variation in the forest canopy structure, e.g., height variation, canopy gap metrics, and lower height percentiles. In this study, RF modeling of vegetation metrics that were derived from the leaf-on DAP point cloud produced the highest accuracy in total biomass (\%RMSE $=12.0$, $\left.R^{2}=0.94\right)$ and broadleaf biomass estimation (\%RMSE $=22.7, R^{2}=0.87$ ), while RF modeling of vegetation metrics that were derived from the leaf-off DAP point cloud produced the highest accuracy in conifer biomass estimation (\%RMSE $\left.=23.8, R^{2}=0.94\right)$. Overall, our results demonstrated that the performance of forest biomass estimation in uneven-aged forests varied considerably with the statistical representation, i.e., SLR, MLR, and RF, as well as with the data source, i.e., leaf-on and leaf-off. Thus, it would be appropriate to explore the relationships between forest structural attributes (response variables) and the vegetation metrics (predictor variables), as well as the potential for different statistical approaches and data sources to reveal information on the behavior of DAP data in uneven-aged forests. Since UAVs are capable of acquiring high-resolution data on demand at the landscape level within a limited period, DAP of UAV imagery, when coupled with adequate field training samples, has good potential for being utilized for the estimation of biomass of large areas. DAP-estimated biomass could be used to produce wall-to-wall maps at the landscape level, which would provide detailed and reliable information for sustainable forest management planning of uneven-aged forest resources. In addition, DAP-estimated forest structural attributes and maps could be used for modeling vegetation dynamics, measuring carbon storage, estimating pre- and post-disturbance forest resources, assessing habitat quality, and quantifying changes in native species.

Author Contributions: Conceptualization, methodology, formal analysis, and writing (original draft preparation), S.J.; resources, supervision, and writing (review and editing), T.O. and S.T.

Funding: This study used the Juro Kawachi Memorial dataset of forest spatial information. In addition, this work was supported by JSPS KAKENHI grant numbers 15K14751, 16H04946, and 17H01516.

Acknowledgments: The authors would like to thank the technical staff of UTHF-Hiroshi Inukai, Hisatomi Kasahara, Hitomi Ogawa, Kota Kimura, Masaki Tokuni, Shinya Inukai, Takashi Inoue, Yoshinori Eguchi, Yuji Nakagawa, Yuji Niwa, and Yukihiro Koike-for their contribution in field and UAV data collection. We thank anonymous reviewers whose comments and suggestions contributed significantly to improve the quality of the manuscript.

Conflicts of Interest: The authors declare no conflicts of interest. 


\section{References}

1. Erb, K.-H.; Kastner, T.; Plutzar, C.; Bais, A.L.S.; Carvalhais, N.; Fetzel, T.; Gingrich, S.; Haberl, H.; Lauk, C.; Niedertscheider, M.; et al. Unexpectedly large impact of forest management and grazing on global vegetation biomass. Nature 2017, 553, 73-76. [CrossRef] [PubMed]

2. Millar, C.I.; Stephenson, N.L.; Stephens, S.L. Climate change and forests of the future: Managing in the face of uncertainty. Ecol. Appl. 2007, 17, 2145-2151. [CrossRef] [PubMed]

3. Boisvenue, C.; Running, S.W. Impacts of climate change on natural forest productivity: Evidence since the middle of the 20th century. Glob. Chang. Biol. 2006, 12, 862-882. [CrossRef]

4. Noss, R.F. Beyond Kyoto: Forest management in a time of rapid climate change. Conserv. Biol. 2001, 15, 578-590. [CrossRef]

5. Kuuluvainen, T.; Tahvonen, O.; Aakala, T. Even-aged and uneven-aged forest management in boreal fennoscandia: A review. Ambio 2012, 41, 720-737. [CrossRef] [PubMed]

6. Pukkala, T.; Lähde, E.; Laiho, O.; Salo, K.; Hotanen, J.-P. A multifunctional comparison of even-aged and uneven-aged forest management in a boreal region. Can. J. For. Res. 2011, 41, 851-862. [CrossRef]

7. Nyland, R. Silviculture: Concepts and Applications; McGraw-Hill: Boston, MA, USA, 2002.

8. Hanewinkel, M. Comparative economic investigations of even-aged and uneven-aged silvicultural systems: A critical analysis of different methods. Forestry 2002, 75, 473-481. [CrossRef]

9. Xie, Y.; Sha, Z.; Yu, M. Remote sensing imagery in vegetation mapping: a review. J. Plant Ecol. 2008, 1, 9-23. [CrossRef]

10. Ma, Z.; Hart, M.M.; Redmond, R.L. Mapping vegetation across large geographic areas: integration of remote sensing and GIS to classify multisource data. Eng. Remote Sens. 2001, 67, 295-307.

11. Kane, V.R.; Bakker, J.D.; McGaughey, R.J.; Lutz, J.A.; Gersonde, R.F.; Franklin, J.F. Examining conifer canopy structural complexity across forest ages and elevations with LiDAR data. Can. J. For. Res. 2010, 40, 774-787. [CrossRef]

12. Brosofske, K.D.; Froese, R.E.; Falkowski, M.J.; Banskota, A. A review of methods for mapping and prediction of inventory attributes for operational forest management. For. Sci. 2014, 60, 733-756. [CrossRef]

13. Wulder, M.A.; Coops, N.C.; Hudak, A.T.; Morsdorf, F.; Nelson, R.F.; Newnham, G.J.; Vastaranta, M. Status and prospects for LiDAR remote sensing of forested ecosystems.pdf. Can. J. Remote Sens. 2013, 39, S1-S5. [CrossRef]

14. Hall, R.J.; Skakun, R.S.; Arsenault, E.J.; Case, B.S. Modeling forest stand structure attributes using Landsat ETM+ data: Application to mapping of aboveground biomass and stand volume. For. Ecol. Manage. 2006, 225, 378-390. [CrossRef]

15. Hyyppä, J.; Yu, X.; Hyyppä, H.; Vastaranta, M.; Holopainen, M.; Kukko, A.; Kaartinen, H.; Jaakkola, A.; Vaaja, M.; Koskinen, J.; Alho, P. Advances in forest inventory using airborne laser scanning. Remote Sens. 2012, 4, 1190-1207. [CrossRef]

16. White, J.C.; Wulder, M.A.; Vastaranta, M.; Coops, N.C.; Pitt, D.; Woods, M. The utility of image-based point clouds for forest inventory: A comparison with airborne laser scanning. Forests 2013, 4, 518-536. [CrossRef]

17. Alonzo, M.; Andersen, H.-E.; Morton, D.; Cook, B. Quantifying boreal forest structure and composition using UAV structure from motion. Forests 2018, 9, 119. [CrossRef]

18. Puliti, S.; Olerka, H.; Gobakken, T.; Næsset, E. Inventory of small forest areas using an unmanned aerial system. Remote Sens. 2015, 7, 9632-9654. [CrossRef]

19. Järnstedt, J.; Pekkarinen, A.; Tuominen, S.; Ginzler, C.; Holopainen, M.; Viitala, R. Forest variable estimation using a high-resolution digital surface model. ISPRS J. Photogramm. Remote Sens. 2012, 74, 78-84. [CrossRef]

20. White, J.C.; Tompalski, P.; Coops, N.C.; Wulder, M.A. Comparison of airborne laser scanning and digital stereo imagery for characterizing forest canopy gaps in coastal temperate rainforests. Remote Sens. Environ. 2018, 208, 1-14. [CrossRef]

21. Zahawi, R.A.; Dandois, J.P.; Holl, K.D.; Nadwodny, D.; Reid, J.L.; Ellis, E.C. Using lightweight unmanned aerial vehicles to monitor tropical forest recovery. Biol. Conserv. 2015, 186, 287-295. [CrossRef]

22. Aicardi, I.; Garbarino, M.; Lingua, A.; Lingua, E.; Marzano, R.; Piras, M. Monitoring post-fire forest recovery using multi-temporal digital surface models generated from different platforms. EARSeL eProceedings 2016, 15, 1-8. [CrossRef] 
23. Tenenbaum, D.E.; Band, L.E.; Kenworthy, S.T.; Tague, C.L. Analysis of soil moisture patterns in forested and suburban catchments in Baltimore using high-resolution photogrammetric and LiDAR digital elevation datasets. Hydrol. Process. An Int. J. 2006, 240, 219-240. [CrossRef]

24. Pierzchała, M.; Talbot, B.; Astrup, R. Estimating soil displacement from timber extraction trails in steep terrain: Application of an unmanned aircraft for 3D modelling. Forests 2014, 5, 1212-1223. [CrossRef]

25. Albertz, J. A Look Back: 140 Years of Photogrammetry. Photogramm. Eng. Remote Sens. 2007, 73, 504-506.

26. Anderson, K.; Gaston, K.J. Lightweight unmanned aerial vehicles will revolutionize spatial ecology. Front. Ecol. Environ. 2013, 11, 138-146. [CrossRef]

27. Watts, A.C.; Ambrosia, V.G.; Hinkley, E.A. Unmanned aircraft systems in remote sensing and scientific research: Classification and considerations of use. Remote Sens. 2012, 4, 1671-1692. [CrossRef]

28. Nex, F.; Remondino, F. UAV for 3D mapping applications: A review. Appl. Geomat. 2014, 6, 1-15. [CrossRef]

29. Mlambo, R.; Woodhouse, I.H.; Gerard, F.; Anderson, K. Structure from motion (SfM) photogrammetry with drone data: A low cost method for monitoring greenhouse gas emissions from forests in developing countries. Forests 2017, 8, 68. [CrossRef]

30. Leberl, F.; Irschara, A.; Pock, T.; Meixner, P.; Gruber, M.; Scholz, S.; Wiechert, A. Point Clouds: Lidar versus 3D Vision. Photogramm. Eng. Remote Sens. 2010, 76, 1123-1134.

31. Wolf, P.R.; Dewitt, B.A. Elements of Photogrammetry: With Applications in Gis, 3rd ed.; McGraw-Hill: New York, NY, USA, 2000; Volume 3, ISBN 0-07-292454-3.

32. Kasser, M.; Egels, Y. Digital Photogrammetry, 2nd ed.; Taylor \& Francis: London, UK, 2002; ISBN 978-3-662-50462-8.

33. Torresan, C.; Berton, A.; Carotenuto, F.; Di Gennaro, S.F.; Gioli, B.; Matese, A.; Miglietta, F.; Vagnoli, C.; Zaldei, A.; Wallace, L. Forestry applications of UAVs in Europe: A review. Int. J. Remote Sens. 2017, 38, 2427-2447. [CrossRef]

34. Gobakken, T.; Bollandsås, O.M.; Næsset, E. Comparing biophysical forest characteristics estimated from photogrammetric matching of aerial images and airborne laser scanning data. Scand. J. For. Res. 2015, 30, 73-86. [CrossRef]

35. Bohlin, J. Data Collection for Forest Management Planning Using Stereo Photogrammetry. 2017. Available online: https:/ / pub.epsilon.slu.se/14752/ (accessed on 7 February 2019).

36. White, J.; Stepper, C.; Tompalski, P.; Coops, N.; Wulder, M.A. Comparing ALS and image-based point cloud metrics and modelled forest inventory attributes in a complex coastal forest environment. Forests 2015, 6, 3704-3732. [CrossRef]

37. Kachamba, D.J.; Ørka, H.O.; Gobakken, T.; Eid, T.; Mwase, W. Biomass estimation using 3D data from unmanned aerial vehicle imagery in a tropical woodland. Remote Sens. 2016, 8, 968. [CrossRef]

38. Cunliffe, A.M.; Brazier, R.E.; Anderson, K. Ultra-fine grain landscape-scale quantification of dryland vegetation structure with drone-acquired structure-from-motion photogrammetry. Remote Sens. Environ. 2016, 183, 129-143. [CrossRef]

39. Puliti, S.; Ene, L.T.; Gobakken, T.; Næsset, E. Use of partial-coverage UAV data in sampling for large scale forest inventories. Remote Sens. Environ. 2017, 194, 115-126. [CrossRef]

40. Fryer, J.; Mclntosh, K. Enhancement of Image Resolution rn Digital Photogrammetry. Available online: https:/ / bit.ly/2MVdR8Z (accessed on 10 February 2019).

41. Li, A.; Dhakal, S.; Glenn, N.F.; Spaete, L.P.; Shinneman, D.J.; Pilliod, D.S.; Arkle, R.S.; McIlroy, S.K. Lidar aboveground vegetation biomass estimates in shrublands: Prediction, uncertainties and application to coarser scales. Remote Sens. 2017, 9, 903. [CrossRef]

42. Bohlin, J.; Bohlin, I.; Jonzén, J.; Nilsson, M. Mapping forest attributes using data from stereophotogrammetry of aerial images and field data from the national forest inventory. Silva Fenn. 2017, 51, 1-18. [CrossRef]

43. Tatewaki, M. Forest Ecology of the Islands of. J. Fac. Agric. Hokkaido Univ. 1958, 50, 371-486.

44. The 13th education and research plan of the university of Tokyo Hokkaido forest (2011-2020). Available online: https:/ / repository.dl.itc.u-tokyo.ac.jp / ?action=pages_view_main\&active_action=repository_view_ main_item_detail\&item_id=26186\&item_no=1\&page_id=28\&block_id=31 (accessed on 8 February 2019).

45. Brief on national forest inventory (NFI), Japan; Rome, 2007; MAR-SFM Working Paper 19/2007. Available online: http:/ / www.fao.org/docrep/016/ap187e/ap187e.pdf (accessed on 8 February 2019).

46. Commonwealth Forestry Association. The commonwealth forestry review; 57 (3). 1978. Available online: https: / / www.jstor.org/stable/42607466?seq=1\#page_scan_tab_contents (accessed on 8 February 2019). 
47. Maezawa, K.; Fukushima, Y.; Nakagawa, I.; Kawahara, S. A report on volume table for broad-leaved trees of Tokyo University Forest in Hokkaido. Misc. Inf. Tokyo Univ. For. 1968, 17, 77-100.

48. Maezawa, K.; Kawahara, S. A preparation of the volume table for Saghalien Fir (Abies sachalinensis) trees of the University Forest in Hokkaido. Bull. Tokyo Univ. For. 1986, 74, 17-37.

49. National Institute for Environmental Studies. National Greenhouse Gas Inventory Report of Japan 2017. Available online: http://www.cger.nies.go.jp/publications/report/i134/i134.pdf (accessed on 8 February 2019).

50. Ota, T.; Ogawa, M.; Shimizu, K.; Kajisa, T.; Mizoue, N.; Yoshida, S.; Takao, G.; Hirata, Y.; Furuya, N.; Sano, T.; et al. Aboveground biomass estimation using structure from motion approach with aerial photographs in a seasonal tropical forest. Forests 2015, 6, 3882-3898. [CrossRef]

51. Bohlin, J.; Wallerman, J.; Fransson, J.E.S. Forest variable estimation using photogrammetric matching of digital aerial images in combination with a high-resolution DEM. Scand. J. For. Res. 2012, 27, 692-699. [CrossRef]

52. McGaughey, R. FUSION/LDV: Software for LIDAR Data Analysis and Visualization. Available online: https:/ / bit.ly/2Gl48Zh (accessed on 8 February 2019).

53. Jayathunga, S.; Owari, T.; Tsuyuki, S. The use of fixed-wing UAV photogrammetry with LiDAR DTM to estimate merchantable volume and carbon stock in living biomass over a mixed conifer-broadleaf forest. Int. J. Appl. Earth Obs. Geoinf. 2018, 73, 767-777. [CrossRef]

54. Jayathunga, S.; Owari, T.; Tsuyuki, S. Evaluating the Performance of Photogrammetric Products Using Fixed-Wing UAV Imagery over a Mixed Conifer-Broadleaf Forest: Comparison with Airborne Laser Scanning. Remote Sens. 2018, 10, 187. [CrossRef]

55. Lisein, J.; Pierrot-Deseilligny, M.; Bonnet, S.; Lejeune, P. A photogrammetric workflow for the creation of a forest canopy height model from small unmanned aerial system imagery. Forests 2013, 4, 922-944. [CrossRef]

56. Probst, A.; Gatziolis, D.; Strigul, N. Intercomparison of photogrammetry software for three-dimensional vegetation modelling. R. Soc. Open Sci. 2018, 5. [CrossRef] [PubMed]

57. Fassnacht, F.E.; Hartig, F.; Latifi, H.; Berger, C.; Hernández, J.; Corvalán, P.; Koch, B. Importance of sample size, data type and prediction method for remote sensing-based estimations of aboveground forest biomass. Remote Sens. Environ. 2014, 154, 102-114. [CrossRef]

58. Baccini, A.; Friedl, M.A.; Woodcock, C.E.; Warbington, R. Forest biomass estimation over regional scales using multisource data. Geophys. Res. Lett. 2004, 31. [CrossRef]

59. Næsset, E.; Økland, T. Estimating tree height and tree crown properties using airborne scanning laser in a boreal nature reserve. Remote Sens. Environ. 2002, 79, 105-115. [CrossRef]

60. Snowdon, P. A ratio estimator for bias correction in logarithmic regression. Can. J. For. Res. 1991, $21,720-724$. [CrossRef]

61. R Development Core Team. R: A Language and Environment for Statistical Computing. Available online: https:/ / bit.ly/2jNQhzW (accessed on 8 February 2019).

62. Breiman, L. Random Forests. Mach. Learn. 2001, 45, 5-32. [CrossRef]

63. Prasad, A.M.; Iverson, L.R.; Liaw, A. Newer classification and regression tree techniques: Bagging and random forests for ecological prediction. Ecosystems 2006, 9, 181-199. [CrossRef]

64. Yu, X.; Hyyppä, J.; Vastaranta, M.; Holopainen, M.; Viitala, R. Predicting individual tree attributes from airborne laser point clouds based on the random forests technique. ISPRS J. Photogramm. Remote Sens. 2011, 66, 28-37. [CrossRef]

65. Liaw, A.; Wiener, M. Classification and Regression by Random Forest. Available online: https:/ / www.rproject.org/doc/Rnews/Rnews_2002-3.pdf (accessed on 8 February 2019).

66. Lisein, J.; Michez, A.; Claessens, H.; Lejeune, P. Discrimination of deciduous tree species from time series of unmanned aerial system imagery. PLoS ONE 2015, 10, 1-20. [CrossRef]

67. Moudrý, V.; Urban, R.; Štroner, M.; Komárek, J.; Brouček, J.; Prošek, J. Comparison of a commercial and home-assembled fixed-wing UAV for terrain mapping of a post-mining site under leaf-off conditions. Int. J. Remote Sens. 2018, 1-18. [CrossRef]

68. Carr, J.C.; Slyder, J.B. Individual tree segmentation from a leaf-off photogrammetric point cloud. Int. J. Remote Sens. 2018, 39, 5195-5210. [CrossRef] 
69. Fankhauser, K.E.; Strigul, N.S.; Gatziolis, D. Augmentation of traditional forest inventory and airborne laser scanning with unmanned aerial systems and photogrammetry for forest monitoring. Remote Sens. 2018, 10, 1562. [CrossRef]

70. Dandois, J.P.; Olano, M.; Ellis, E.C. Optimal altitude, overlap, and weather conditions for computer vision uav estimates of forest structure. Remote Sens. 2015, 7, 13895-13920. [CrossRef]

71. Dandois, J.P.; Baker, M.; Olano, M.; Parker, G.G.; Ellis, E.C. What is the Point? Evaluating the structure, color, and semantic traits of computer vision point clouds of vegetation. Remote Sens. 2017, 9, 355. [CrossRef]

72. Biau, G.; Scornet, E. A Random Forest Guided Tour. Available online: https://arxiv.org/abs/1511.05741 (accessed on 8 February 2019).

73. Kattenborn, T.; Hernández, J.; Lopatin, J.; Kattenborn, G.; Fassnacht, F.E. Pilot study on the retrieval of dbh and diameter distribution of deciduous forest stands using cast shadows in UAV-based orthomosaics. ISPRS Ann. Photogramm. Remote Sens. Spat. Inf. Sci. 2018, 4, 93-99. [CrossRef]

74. Torres-Sánchez, J.; de Castro, A.I.; Peña, J.M.; Jiménez-Brenes, F.M.; Arquero, O.; Lovera, M.; López-Granados, F. Mapping the 3D structure of almond trees using UAV acquired photogrammetric point clouds and object-based image analysis. Biosyst. Eng. 2018, 176, 172-184. [CrossRef]

75. Bohlin, J.; Wallerman, J.; Fransson, J.E.S. Deciduous forest mapping using change detection of multi-temporal canopy height models from aerial images acquired at leaf-on and leaf-off conditions. Scand. J. For. Res. 2016, 31, 517-525. [CrossRef]

76. Dandois, J.P.; Ellis, E.C. High spatial resolution three-dimensional mapping of vegetation spectral dynamics using computer vision. Remote Sens. Environ. 2013, 136, 259-276. [CrossRef]

(C) 2019 by the authors. Licensee MDPI, Basel, Switzerland. This article is an open access article distributed under the terms and conditions of the Creative Commons Attribution (CC BY) license (http:// creativecommons.org/licenses/by/4.0/). 